\title{
Lhx6 Activity Is Required for the Normal Migration and Specification of Cortical Interneuron Subtypes
}

\author{
Petros Liodis, ${ }^{1}$ Myrto Denaxa, ${ }^{1}$ Marirena Grigoriou, ${ }^{1}$ Cynthia Akufo-Addo, ${ }^{1}$ Yuchio Yanagawa,,${ }^{2}$ and Vassilis Pachnis ${ }^{1}$ \\ ${ }^{1}$ Division of Molecular Neurobiology, Medical Research Council National Institute for Medical Research, London NW7 1AA, United Kingdom, and \\ ${ }^{2}$ Department of Genetic and Behavioral Neuroscience, Gunma University Graduate School of Medicine and Solution-Oriented Research for Science and \\ Technology, Maebashi 371-8511, Japan
}

The cerebral cortex contains two main neuronal cell populations, the excitatory glutamatergic (pyramidal) neurons and the inhibitory interneurons, which synthesize GABA and constitute $20-30 \%$ of all cortical neurons. In contrast to the mostly homogeneous population of projection neurons, cortical interneurons are characterized by remarkable morphological, molecular, and functional diversity. Among the markers that have been used to classify cortical interneurons are the calcium-binding proteins parvalbumin and calretinin and the neuropeptide somatostatin, which in rodents identify mostly nonoverlapping interneuron subpopulations. Pyramidal neurons are born during embryogenesis in the ventricular zone of the dorsal telencephalon, whereas cortical interneurons are generated in the subpallium and reach the cortex by tangential migration. On completion of tangential migration, cortical interneurons switch to a radial mode of migration and enter the cortical plate. Although the mechanisms that control the generation of interneuron diversity are currently unknown, it has been proposed that their site of origin in the ventral forebrain determines their specification into defined neurochemical subgroups. Here, we show that $\operatorname{Lh} x 6$, a gene induced in the medial ganglionic eminence and maintained in parvalbumin- and somatostatin-positive interneurons, is required for the specification of these neuronal subtypes in the neocortex and the hippocampus. We also show that Lhx6 activity is required for the normal tangential and radial migration of GABAergic interneurons in the cortex.

Key words: calretinin; forebrain; interneuron; Lhx6; LIM homeodomain; neocortex; parvalbumin; somatostatin

\section{Introduction}

GABA-producing inhibitory interneurons play a key role in the function of the cerebral cortex by modulating the activity of the principal excitatory pyramidal neurons and thus facilitating the functional integration of neuronal networks (Kawaguchi and Kubota, 1997; Whittington and Traub, 2003; Markram et al., 2004; Ben-Ari and Holmes, 2005). In rodents, GABAergic neurons constitute $\sim 20-30 \%$ of cortical neurons and are distributed uniformly throughout the cortical plate (Kawaguchi and Kubota, 1997; Markram et al., 2004). In contrast to the mostly homogeneous population of pyramidal neurons, cortical interneurons are characterized by diverse molecular, morphological, and physiological properties (Ramon y Cajal, 1911; Yuste, 2005). Thus, based on expression of the calcium-binding proteins parvalbu$\min (\mathrm{Pv})$, calbindin $(\mathrm{Cb})$, and calretinin $(\mathrm{Cr})$ and the neuropep-

Received July 19, 2006; revised Jan. 11, 2007; accepted Feb. 6, 2007

This work was supported by the Medical Research Council and the European Commission through Specific Targeted Research Project Contract 005139 of the Cortical Interneuron Development Consortium. We thank Sarah Clayton for excellent technical assistance. We also thank Drs. M. Gassmann and P. LeTissier for probes.

Correspondence should be addressed to Vassilis Pachnis, Division of Molecular Neurobiology, Medical Research Council National Institute for Medical Research, The Ridgeway, Mill Hill, London NW7 1AA, UK. E-mail: vpachni@nimr.mrc.ac.uk.

M. Grigoriou's present address: Department of Molecular Biology and Genetics, Democritus University of Thrace, Dimitras 19, 68100 Alexandroupolis, Greece.

C. Akufo-Addo's present address: Murine Molecular Constructs Laboratory, Center for Comparative Medicine, County Road 98 and Hutchinson Drive, Davis, CA 95616.

D0I:10.1523/JNEUROSCI.3055-06.2007

Copyright $\odot 2007$ Society for Neuroscience $\quad$ 0270-6474/07/273078-12\$15.00/0 tide somatostatin (Sst), cortical interneurons in rodents are subdivided into three mostly nonoverlapping populations, namely $\mathrm{Pv}^{+}, \mathrm{Sst}^{+} / \mathrm{Cb}^{+}$, or $\mathrm{Cr}^{+}$(DeFelipe, 1993; Kubota et al., 1994; Gonchar and Burkhalter, 1997; Kawaguchi and Kubota, 1997; Markram et al., 2004; Somogyi and Klausberger, 2005).

Unlike pyramidal neurons, which are born in the dorsal telencephalon, the majority of cortical interneurons in mice are generated in the medial ganglionic eminence (MGE) of the ventral forebrain, between embryonic day 12.5 (E12.5) and birth, and reach the cortex by tangential migration (de Carlos et al., 1996; Anderson et al., 1997; Tamamaki et al., 1997; Lavdas et al., 1999; Sussel et al., 1999; Wichterle et al., 1999; Pleasure et al., 2000; Marin and Rubenstein, 2003; Valcanis and Tan, 2003). The first population of interneurons emerging from the MGE $(\sim \mathrm{E} 12.5)$ invade the cortex via the marginal zone $(\mathrm{MZ})$, whereas subsequent waves of GABAergic interneurons populate the lower intermediate and subventricular zones (IZ/SVZ) (Corbin et al., 2001; Jimenez et al., 2002; Nadarajah and Parnavelas, 2002; Marin and Rubenstein, 2003; Tanaka et al., 2003). On completion of tangential migration, cortical interneurons switch to a radial mode of migration, invade the cortical plate, and are distributed uniformly throughout the cortical layers (Nadarajah et al., 2002; Ang et al., 2003; Tanaka et al., 2003; Metin et al., 2006). In addition to the MGE, the lateral ganglionic eminence (LGE) also contributes to the neocortical population of interneurons (de Carlos et al., 1996; Tamamaki et al., 1997; Anderson et al., 2001; Jimenez et al., 2002). Finally, in vivo fate mapping studies 
have established that the most posterior extension of the ganglionic eminences, the caudal ganglionic eminence (CGE), a structure molecularly distinct from the MGE and LGE, contributes a subpopulation of interneurons to the neocortex and the hippocampus (Nery et al., 2002; Yozu et al., 2005). Despite considerable progress toward the classification and characterization of cortical interneurons, the molecular and cellular mechanisms that control their migration during embryogenesis and the generation of subtype diversity are currently unclear (Flames and Marin, 2005).

Lin-11, Isl-1, and Mec-3 (LIM) were the first identified members of the LIM homeodomain transcription factors family. These transcription factors have critical roles in cell fate decisions and neuronal subtype specification in diverse organisms (Hobert and Westphal, 2000; Shirasaki and Pfaff, 2002). A recently identified subfamily of LIM homeodomain encoding genes, $L h x 6$ and $L h x 7$ (also known as $L h x 8$ and $L 3$ ), are expressed during embryogenesis in neuroectodermal cells of the first branchial arch and in the MGE and the AEP (anterior endopenducular area) of the ventral telencephalon (Matsumoto et al., 1996; Grigoriou et al., 1998; Kitanaka et al., 1998). More specifically, Lhx6 is expressed in tangentially migrating GABAergic interneurons (Grigoriou et al., 1998; Kimura et al., 1999; Lavdas et al., 1999; Choi et al., 2005) and its activity is required for the migration of these cells in organotypic slice preparations (Alifragis et al., 2004). Despite these studies, the role of $L h x 6$ in the specification and migration of cortical interneurons in vivo is currently unknown.

Here, we demonstrate that $L h x 6$ is preferentially expressed in the $\mathrm{Pv}$ - and Sst-expressing subpopulations of cortical interneurons and is required in vivo for their specification. In addition, our experiments show that $\operatorname{Lh} x 6$ is required for the normal pattern of tangential migration of GABAergic interneuron progenitors and for their correct distribution in the cortical layers of postnatal animals.

\section{Materials and Methods}

Animals. The $L h x 6^{\text {LacZins }}$ and $L h x 6^{-}$alleles were generated using a similar targeting vector. The $5^{\prime}$ homology is made up from a $3.1 \mathrm{~kb} K p n \mathrm{I}-\mathrm{NcoI}$ fragment containing the $5^{\prime}$ upstream region and the first exon of $L h x 6$, whereas the $3^{\prime}$ homology is made up from a $6 \mathrm{~kb}$ Aat II-NsiI fragment that contains part of exon 5 and exons $6-8$. For the $\operatorname{Lh} x 6^{-}$targeting vector, the $12.3 \mathrm{~kb}$ genomic fragment between the homology regions is replaced by a $7 \mathrm{~kb}$ cassette, containing the following: (1) the encephalomyocarditis virus (ECMV)-internal ribosome entry site (IRES) sequence followed by a cDNA encoding enhanced green fluorescent protein (eGFP) and a polyadenylation signal, and (2) the neomycin resistance gene under the control of the phosphoglycerate kinase (PGK) promoter (PGK-Neo) flanked by loxP sites. The construct also contains the HSV-TK (herpes simplex virus-thymidine kinase) gene for double selection of clones. In the Lhx $6^{\text {LacZins }}$ targeting vector, the eGFP cDNA was replaced by $L a c Z$. Targeting constructs were linearized and electroporated into E14Tg2A embryonic stem (ES) cells. Targeted clones were identified and analyzed in detail by Southern blotting using the $5^{\prime}$ and $3^{\prime}$ external probes indicated in Figure $3 A$. Germline transmission of the mutant alleles was achieved using standard protocols. The phenotypic analysis presented was performed on animals from which the PGK-Neo cassette was removed by crossing founder $L h x 6^{-}$animals with the Prm 1Cre transgenic line, in which the bacterial recombinase Cre is expressed under the control of the protamine-1 promoter (O'Gorman et al., 1997). For the maintenance of the $L h x \sigma^{-}$colony and identification of all potential genotypes, we performed PCR using combinations of primers specific for the GFP (5'-GTCAGTGGAGAGGGTGAAGGTG-3' and 5' GGCAGATTGTGTGGACAGGTAATGG-3') and wild-type Lhx6 (5' AGGCGCTCTGGACAAGGACGAA- ${ }^{\prime}$ and $5^{\prime}$-TGGAACCGGGGCAAAAGGAGAC- $3^{\prime}$ ) sequences. Additional details for the construct and genotyping of animals are available on request.
The Lhx $6^{\text {LacZins }}$ allele was propagated in the heterozygous state by continuous backcrossing to C57BL/6 inbred mice. The $L h x 6^{-}$colony was also maintained by backcrossing to C57BL/6 animals. Homozygous Lhx $6^{-}$embryos and postnatal animals were generated by intercrossing heterozygous mice. For timed pregnancies, the day of vaginal plug detection was considered E0.5.

RNA in situ hybridization. Nonradioactive in situ hybridization on fresh frozen or fixed cryostat sections was performed as described previously (Schaeren-Wiemers and Gerfin-Moser, 1993). Riboprobes used were specific for $\operatorname{Lhx} 6$ (Grigoriou et al., 1998), Gad1 (Casarosa et al., 1999), and Dlx2 (Bulfone et al., 1993). The riboprobe for ErbB4 (kindly provided by Dr. M. Gassmann, Department of Physiology, Biozentrum/ Pharmazentrum, University of Basel, Basel, Switzerland) corresponds to $651 \mathrm{bp}$ of the $5^{\prime}$-end of the murine cDNA. The riboprobe for Sst (kindly provided by Dr. P. LeTissier, Division of Molecular Neuroendocrinology, National Institute for Medical Research, London, UK) is a PCRamplified $276 \mathrm{bp}$ fragment from rat Sst cDNA.

Histology. For histological analysis, brains of 2-week-old [postnatal day 15 (P15)] animals were fixed in neutral buffered formalin for $48 \mathrm{~h}$ (at $4^{\circ} \mathrm{C}$ ), dehydrated, and embedded in paraffin. Samples were sectioned serially at $7 \mu \mathrm{m}$. Sections were stained with hematoxylin-eosin or cresyl violet.

Organotypic brain slice and organ culture. Forebrain slice cultures and labeling by the vital dye $1,1^{\prime}$-dioctadecyl-3,3,3',3'-tetramethylindocarbocyanine perchlorate (DiI) were performed essentially as described previously (Denaxa et al., 2001). Briefly, brains from E13.5-E14.5 Lh $x 6^{+/-}$or $L h x 6^{-/-}$embryos were dissected in cold L15 medium supplemented with $100 \mathrm{U} / \mathrm{ml}$ penicillin/streptomycin (Invitrogen, San Diego, CA) and embedded in $2.5 \%$ low melting agarose (Sigma, St. Louis, MO). Vibratome (Leica, Nussloch, Germany) sections $(250 \mu \mathrm{m})$ were placed on organotypic membranes (Millicell-CM 30; PICM ORG 50; Millipore, Bedford, MA) and cultured in DMEM/F12/10\% fetal calf serum (FCS) medium (supplemented with $1 \mathrm{~mm}$ L-glutamine, N2 supplement, $100 \mathrm{U} / \mathrm{ml}$ penicillin/streptomycin, and $10 \mu \mathrm{g} / \mathrm{ml}$ ciprofloxacin; all from Invitrogen) for $1 \mathrm{~h}$ at $37^{\circ} \mathrm{C}$ in $5 \% \mathrm{CO}_{2}$. After placing a small DiI crystal in the SVZ of the MGE, slices were further cultured in Neurobasal medium (supplemented with B27 and N2, 1 mM L-glutamine, $100 \mathrm{U} / \mathrm{ml}$ penicillin/streptomycin, and $10 \mu \mathrm{g} / \mathrm{ml}$ ciprofloxacin) for $48 \mathrm{~h}$. At the end of the culture period, slices were fixed in $4 \%$ paraformaldehyde (PFA) and $80 \mu \mathrm{m}$ vibratome (Leica) sections were analyzed by confocal microscopy (Bio-Rad, Hercules, CA).

MGE explants were prepared from forebrain slices derived from E13.5 mouse embryos (see Fig. $8 D$ ) generated by $L h x \sigma^{-}$heterozygous intercrosses. Small tissue fragments corresponding to the VZ/SVZ of the MGE were incubated for $1 \mathrm{~h}$ in L15/10\% FCS at $37^{\circ} \mathrm{C}$ in $5 \% \mathrm{CO}_{2}$. Subsequently, explants were placed in a three-dimensional collagen gel matrix and cultured for $48 \mathrm{~h}$ in Neurobasal medium in four-well plates (Nunc, Naperville, IL) as described previously (Metin et al., 1997; Natarajan et al., 2002). Explants were then fixed in $4 \%$ PFA and analyzed using an epifluorescence microscope (Axiophot/Zeiss, Oberkochen, Germany).

Immunostaining and Western blot analysis. For immunostaining, animals were perfused with $4 \%$ PFA and dissected brains were immersed in the same fixative overnight. Vibratome sections $(50 \mu \mathrm{m})$ were permeabilized in $0.5 \%$ Triton X-100 in PBS [30 min at room temperature (RT)], washed in PBT (0.1\% Triton X-100 in PBS), blocked in $10 \%$ FCS, $1 \% \mathrm{BSA}$ in $\mathrm{PBT}(3 \mathrm{~h} ; \mathrm{RT})$, and incubated with primary antibodies diluted in $1 \% \mathrm{FCS}, 0.1 \% \mathrm{BSA}$ in PBT for $36 \mathrm{~h}$ at $4^{\circ} \mathrm{C}$. After washing in PBT (six times for 15 min each time; RT), sections were incubated with secondary antibodies (for $2 \mathrm{~h}$ at RT), washed in PBT, and mounted using Vectashield mounting medium. Embryonic tissue was fixed overnight in $4 \%$ PFA, and cryostat sections $(14 \mu \mathrm{m})$ were processed as above, omitting the permeabilization step. The following antibodies were used: rabbit polyclonal anti-Lhx6 (1:250-1000) (Lavdas et al., 1999), mouse monoclonal anti-parvalbumin (Chemicon, Temecula, CA; 1:1000), rabbit polyclonal anti-calbindin (Chemicon; 1:3000), and rabbit polyclonal anti-calretinin (Chemicon; 1:1000). For $\beta$-galactosidase ( $\beta$-gal) detection, three different antibodies were used: mouse monoclonal (Sigma; 1:150), mouse monoclonal (Promega, Madison, WI; 1:200), and rabbit polyclonal (Cappel, Cochranville, PA; 1:1500). GFP was detected using a mouse 
monoclonal antibody (Invitrogen; 1:500) or a rabbit polyclonal antibody (Invitrogen; 1:500). Secondary antibodies used are as follows: Alexa Fluor 488-conjugated goat anti-mouse and anti-rabbit and Alexa Fluor 568-conjugated goat anti-mouse and anti-rabbit (all from Invitrogen; all 1:500).

For Western blot analysis, forebrain from individual E15.5 embryos was homogenized in $300 \mu \mathrm{l}$ of non-denaturing buffer [ $50 \mathrm{~mm}$ Tris, $\mathrm{pH}$ 7.5, $50 \mathrm{~mm} \mathrm{NaCl}, 5$ mм EDTA, 1\% IGEPAL; complete protease inhibitors (Roche, Basel, Switzerland) added according to manufacturer's instructions] and incubated for $15 \mathrm{~min}$ on ice. After centrifugation (13,000 rpm; $10 \mathrm{~min} ; 4^{\circ} \mathrm{C}$ ), the cleared lysates were electrophoresed in $10 \%$ SDS polyacrylamide gel and electrotransferred to polyvinylidene difluoride membranes (Millipore) using standard protocols. Membranes were subsequently immunoblotted with rabbit anti-Lhx6 (Lavdas et al., 1999) and goat anti-actin antibodies (catalog \#SC-1615; Santa Cruz Biotechnology, Santa Cruz, CA).

Quantification. Colocalization of $\beta$-gal with Lhx6 and other markers of cortical interneuron subtypes ( $\mathrm{Pv}, \mathrm{Sst}$, and $\mathrm{Cr}$ ), and GFP was evaluated in three adult $L h x 6^{+/ \text {LacZins }}$ mice. Briefly, a series of optical sections $2 \mu \mathrm{m}$ apart were captured at equivalent regions of the dorsal telencephalon using a Bio-Rad/Radiance 2100 confocal laser-scanning microscope. Optical sections were then assembled into $50 \mu \mathrm{m} Z$-stacks and analyzed using the LaserSharp 2000 program (Bio-Rad). More than 650 cells were evaluated for each marker. Analysis was performed at five different bregma positions along the rostrocaudal axis: $1.18,0.74,0.14,-1.94$, and -2.80 (Paxinos and Franklin, 2001). For the colocalization of Lhx6 and GFP in E15.5 GAD67-GFP embryos, $14 \mu \mathrm{m}$ brain sections representing the entire rostrocaudal extent of the telencephalon were immunostained with the corresponding antibodies and analyzed by confocal laser microscopy (Bio-Rad). A minimum of $500 \mathrm{GFP}^{+}$cells were examined for expression of Lhx6.

The number of $\mathrm{GAD} 7^{+}$cells was evaluated in the primary motor, primary sensory, and barrel cortex of 2-week-old (P15) mutant $\left(\operatorname{Lh} x 6^{-/-} ; n=4\right)$ and control $\left(\operatorname{Lhx} 6^{+/-} ; n=4\right)$ animals. In each region, we counted the number of GAD $67^{+}$cells present in $1000-\mu \mathrm{m}$-wide cortical columns on $16 \mu \mathrm{m}$ sections spaced $300 \mu \mathrm{m}$ apart along the rostrocaudal axis. To minimize counting bias, we compared sections of equivalent bregma positions, defined according to the mouse brain atlas (Paxinos and Franklin, 2001). The number of GAD67 ${ }^{+}$cells in the CA1 region of hippocampus proper was evaluated in $1000-\mu \mathrm{m}$-wide columns (16 $\mu \mathrm{m}$ sections; $300 \mu \mathrm{m}$ apart). The corpus callosum and the hippocampal fissure were used as borders of the hippocampus proper. In all cases, data are given as mean \pm SEM, and the effect of the genotype on the number of GAD67 ${ }^{+}$cells was assessed using the Student test ( $t$ test).

The distribution of GAD $67^{+}$cells was evaluated in the primary motor, primary sensory, and barrel cortex of control $(n=4)$ and mutant $(n=4)$ animals. Briefly, cortical columns of comparable width at equivalent rostrocaudal levels were divided in 10 horizontal bins and the number of GAD $67^{+}$cells in each bin was counted. Data are given as percentages of the total $\mathrm{GAD} 7^{+}$cell population present in each bin (mean $\pm \mathrm{SEM}$ ). The laminar distribution of GAD $67^{+}$cells was also evaluated in the CA1 region the hippocampus. In both cases, the effect of the genotype on the distribution of cells within the bins was assessed using the Student test $(t$ test). The statistical significance of the difference in the distribution of cells in control and mutant cortex was also evaluated using Pearson's $\chi^{2}$ test $\left(\chi^{2} \gg p=0.001\right.$ for the null hypothesis; namely, similar distribution of cells in both control and mutant animals).

The number of $\mathrm{Pv}^{+}, \mathrm{Sst}^{+}$, and $\mathrm{Cr}^{+}$cells in cortical columns of 1000 $\mu \mathrm{m}$ width was evaluated in the primary motor, primary sensory, and barrel cortex of $n=4$ pairs of 2-week-old (P15) control $\left(\right.$ Lhx $6^{+/+}$or Lh $\left.x 6^{+/-}\right)$and mutant $\left(\operatorname{Lh} x 6^{-/-}\right)$animals at similar rostrocaudal levels [according to Paxinos and Franklin (2001)]. The number of $\mathrm{Cr}^{+}$cells was also evaluated in the CA1 region of the hippocampus. Data are given as mean \pm SEM, and the statistical significance was assessed by the Student test ( $t$ test).

To quantify the effect of the $\operatorname{Lhx6^{-}}$ mutation on the migration of MGE cells in collagen gel cultures (see Fig. 8), we selected the 24 cells positioned furthest away from the center of each explant and measured their distance from its edge using MetaMorph software package (Molecular Devices, Sunnyvale, CA) (five embryos for each genotype and four explants established for each embryo). The average value of these measurements represented the maximum distance of cell migration from each explant.

\section{Results}

\section{Transgenic reporter mouse strains}

During mouse embryogenesis, Lhx6 is expressed in the ventral forebrain and in tangentially migrating cells in the cortex, and Lhx6-specific riboprobes and antibodies have been used previously to identify progenitors of cortical interneurons (Lavdas et al., 1999; Alifragis et al., 2004). Our current studies focus on the expression of $\operatorname{Lh} x 6$ in specific subpopulations of cortical interneurons and its role in neuronal cell migration and subtype specification in the telencephalon. For these experiments, we used several transgenic mouse strains, including two reporter lines, which we characterize here relative to $\operatorname{Lh} x 6$ expression. The first reporter strain was generated during our efforts to engineer a deletion of $L h x 6$ by homologous recombination in ES cells. These experiments led unexpectedly to the generation of a mutant allele (called thereafter $\operatorname{Lh} \times 6^{\text {LacZins }}$ ) in which the entire targeting construct (including the reporter $\operatorname{Lac} Z$ cDNA) was inserted at the $3^{\prime}$ end of Lhx6 (data not shown). Consistent with the minimal disruption of the Lhx6 coding sequences, both heterozygous and homozygous $\operatorname{Lh} x 6^{\text {LacZins }}$ animals were viable, morphologically normal, and fertile. By comparing the distribution of $\beta$-gal and Lhx6 mRNA during embryogenesis and in adult Lhx $6^{\text {LacZins }}$ animals, we established that $L a c Z$ was under the control of the regulatory sequences of $\operatorname{Lh} x 6$. On brain sections from E12.5 Lhx $6^{+/}$ LacZins embryos, Lhx6 transcripts were detected in a few cells in the ventricular zone and in a large cohort of cells in the subventricular and mantle zones of the MGE (Fig. $1 \mathrm{~A}$ ). At this stage, a small number of Lhx6-expressing cells were also detected in the LGE and represent the forerunners of the tangentially migrating population of cortical interneurons (Fig. $1 A$, arrowhead). $\beta$-Gal histochemistry on equivalent sections from $\operatorname{Lh} x 6^{+/ \text {LacZins }}$ embryos showed a similar distribution of LacZ-expressing cells (Fig. $1 B$ ). A similar distribution of $\mathrm{Lhx}^{+}$and $\beta$-gal ${ }^{+}$cells was also observed in the forebrain of E14.5 and E16.5 Lhx $6^{+/ \text {LacZins }}$ embryos (Fig. $1 C-F$ ). At postnatal stages, $\mathrm{Lhx}^{+}$cells were present throughout the neocortex and in specific layers of the hippocampus, namely the stratum oriens (so) and the pyramidal cell layers ( $\mathrm{pcl}$ ) of the CA1-CA3 regions of hippocampus proper and the polymorphic layer (po) of the dentate gyrus (Fig. 1G,I). A similar distribution of $\beta$-gal ${ }^{+}$cells was observed in the neocortex and the hippocampus of $\operatorname{Lh} x 6^{+/ \text {LacZins }}$ animals (Fig. 1, compare $G$ and $I$ with $H$ and $J$, respectively). To further establish the coexpression of $L h x 6$ and the $L a c Z$ reporter, we immunostained brain sections from $\operatorname{Lh} x 6^{+/ \text {LacZins }}$ animals with antibodies specific for Lhx6 and $\beta$-gal. We found that almost all (>95\%) Lhx6-positive cells in the cortex coexpressed $\beta$-gal, whereas $>97 \%$ of $\beta$-gal ${ }^{+}$cells were also positive for Lhx6 (Fig. $1 K-M$ ). These findings demonstrate that, in the telencephalon of $L h x 6^{+/ \text {LacZins }}$ animals, expression of $L a c Z$ is a faithful reporter of $L h x 6$-expressing cells.

During embryogenesis, $L h x 6$ is expressed in tangentially migrating GABAergic neurons that colonize the neocortex and the hippocampus (Lavdas et al., 1999; Alifragis et al., 2004; Legaz et al., 2005). However, it is currently unclear whether $L h x 6$ marks the entire population of cortical interneurons. To explore this issue, we analyzed a second mouse transgenic line (GAD67GFP $\Delta$ neo; called hereafter Gad67-GFP) in which an eGFP cDNA cassette has been inserted into the Gad1 locus, which encodes the 

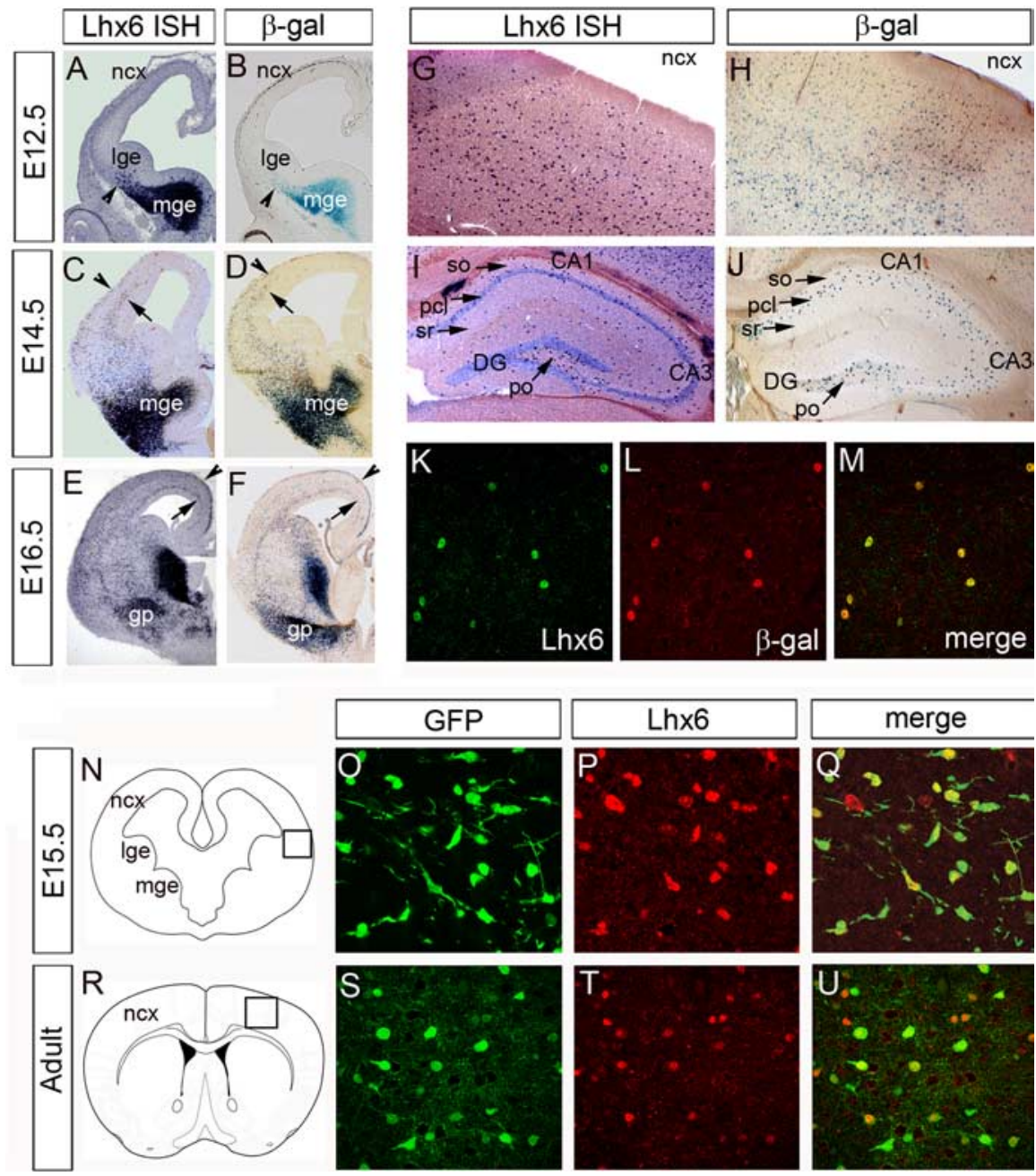

Figure 1. $\boldsymbol{A}-\boldsymbol{J}$, Expression of the $L h \times 6^{\text {LacZins }}$ allele recapitulates the pattern of expression of the wild-type Lhx6 locus. Coronal sections from the forebrain of E12.5 $(\boldsymbol{A}, \boldsymbol{B}), \mathrm{E} 14.5(\boldsymbol{C}, \boldsymbol{D})$, and E16.5 $(\boldsymbol{E}, \boldsymbol{F})$ Lhx6 ${ }^{+/ \text {LacZins }}$ embryos or the neocortex $(\boldsymbol{G}, \boldsymbol{H})$ and the hippocampus $(\boldsymbol{I}, \boldsymbol{J})$ of $L h \times 6^{+/ \text {LacZins }}$ adult animals were processed either for in situ hybridization with a Lhx6-specific riboprobe $(\boldsymbol{A}$ $\boldsymbol{C}, \boldsymbol{E}, \boldsymbol{G}, \boldsymbol{I})$ or $\beta$-gal histochemistry $(\boldsymbol{B}, \boldsymbol{D}, \boldsymbol{F}, \boldsymbol{H}, \boldsymbol{J})$. The arrowheads in $\boldsymbol{A}$ and $\boldsymbol{B}$ point to the early population of MGE-derived cells that migrate toward the cortex. The arrowheads and arrows in $\mathbf{C}-\boldsymbol{F}$ indicate the $\mathrm{MZ}$ and IZ/SVZ, respectively. Note the similar distribution of cells identified by in situ hybridization and $\beta$-gal histochemistry. $\boldsymbol{K}-\boldsymbol{M}$, A cortical section from an $L$ hx $\sigma^{+/ L a c Z i n s}$ adult animal double immunostained with antibodies specific for $\operatorname{Lhx6}(\boldsymbol{K})$ and $\beta$-gal $(\boldsymbol{L})$. As shown by the merged image $(\boldsymbol{M})$, all Lhx6 ${ }^{+}$cells coexpress $\beta$-gal. $\boldsymbol{N}-\boldsymbol{U}$, Brain sections from E15.5 (N-Q) and adult $(\boldsymbol{R}-\boldsymbol{U})$ GAD67GFP animals immunostained for GFP $(\mathbf{O}, \mathbf{S})$ and Lhx6 $(\boldsymbol{P}, \boldsymbol{T})$. The corresponding merged images are shown in $\mathbf{Q}$ and $\boldsymbol{U}$. The areas shown in $\mathbf{0} \mathbf{Q}$ and $\mathbf{S}-\boldsymbol{U}$ correspond to the boxes shown in $\boldsymbol{N}$ and $\boldsymbol{K}$, respectively. $\beta$-gal, $\beta$-Galactosidase; gb, globus pallidus; ISH, in situ hybridization; Ige, lateral ganglionic eminence; mge, medial ganglionic eminence; ncx, neocortex; poDG, polymorphic layer of the dentate gyrus; pcl, pyramidal cell layer; so, stratum oriens; sr, stratum radiatum.

$67 \mathrm{kDa}$ isoform of glutamate decarboxylase (Gad67) (Erlander et al., 1991; Tanaka et al., 2003, 2006). Double immunostaining for GFP and Lhx6 on brain sections from E15.5 heterozygous Gad67GFP embryos showed that at this stage virtually all Lhx6 ${ }^{+}$cells were also positive for GFP and that the vast majority (96.8 \pm $0.8 \%$ ) of $\mathrm{GFP}^{+}$cells in the neocortex and hippocampus coexpress $\operatorname{Lh} x 6$ (Fig. $1 \mathrm{~N}-\mathrm{Q}$ ). Similar to the embryonic stages, virtually all Lhx6 ${ }^{+}$cortical cells in the adult cortex were also positive for GFP (Fig. $1 R-U$ ). However, only $74.3 \pm 1.6 \%$ of $\mathrm{GFP}^{+}$cells expressed $L h x 6$. These studies indicate that during forebrain development, expression of $L h x 6$ is progressively restricted to subsets of cortical interneurons, raising the possibility that the gene is preferentially expressed in the early-born subtypes of GABAergic interneurons.
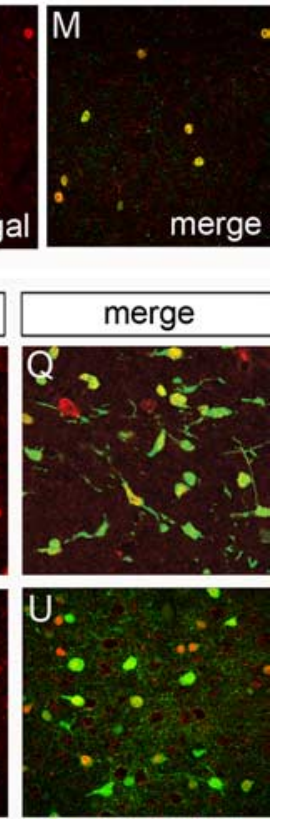

Lhx6 preferentially marks the $\mathrm{Pv}$ - and Sst-expressing subpopulations of cortical interneurons

To identify the subpopulation(s) of cortical interneurons that express $\operatorname{Lh} x 6$, brain sections from adult $\operatorname{Lh} x 6^{+/ \text {LacZins }}$ animals were double immunostained with antibodies for $\beta$-gal and the calcium binding proteins $\mathrm{Pv}$ and $\mathrm{Cr}$ and the neuropeptide Sst, markers that identify mostly nonoverlapping subpopulations of cortical interneurons (Kawaguchi and Kubota, 1997; Markram et al., 2004). The vast majority of $\mathrm{PV}^{+}$neurons in the neocortex and the hippocampus of Lhx $6^{+/ \text {LacZins }}$ animals express $\operatorname{Lhx} 6(90.0 \pm 0.7$ and $88.9 \pm 2.5 \%$, respectively) (Fig. $2 A-C$ and data not shown). A high degree of coexpression was also observed between Sst and Lhx6. Thus, $95.4 \pm 0.6 \%$ of Sst $^{+}$cells in the neocortex and $92.0 \pm 0.7 \%$ of Sst ${ }^{+}$cells in the hippocampus were also positive for $\beta$-gal (Fig. 2D-F) (data not shown). Compared with $\mathrm{Pv}^{+}$and $\mathrm{Sst}^{+}$cells, a smaller fraction of $\mathrm{Cr}^{+}$cells coexpressed Lhx6 (overall $61.7 \pm 0.9 \%$ in the neocortex and $53.0 \pm$ $7.5 \%$ in the hippocampus) (Fig. 2G-I). However, the subpopulation of bipolar cells expressing high levels of $\mathrm{Cr}\left(\mathrm{Cr}^{+ \text {high }}\right)$ (DeFelipe, 1993; Kubota et al., 1994; Porter et al., 1998; Butt et al., 2005) were generally (>93\%) negative for $\beta$-gal (Fig. $2 \mathrm{H}$, arrow). In contrast, the majority (75.6 \pm $0.9 \%$ ) of non-bipolar cells (which constitute $\sim 45 \%$ of the total $\mathrm{Cr}^{+}$population and generally expressed $\mathrm{Cr}$ at lower levels) coexpressed $\beta$-gal. Together, our experiments indicate that $L h x 6$ preferentially identifies $\mathrm{Pv}^{+}$and $\mathrm{Sst}^{+}$cortical interneurons, but it is generally excluded from $\mathrm{Cr}^{+}$ high bipolar interneurons.

\section{Generation of Lhx6 mutant animals}

To investigate the potential role of $L h x 6$ in cortical interneuron development, we used homologous recombination in ES cells to generate a mutant allele of the locus (called thereafter $\operatorname{Lh} x 6^{-}$). Our targeting strategy (shown in Fig. $3 A$ and described in detail in Materials and Methods) was designed to delete exons 2-4 and part of exon 5 (encoding the LIM domains and the first 17 amino acids of the homeodomain; www.ensembl.org) and replace them with an IRES-GFP reporter cassette. Correctly targeted ES clones were identified (Fig. $3 B$ ) and animals heterozygous for the $\operatorname{Lhx} 6^{-}$mutation were generated. $L h x 6^{+/-}$animals develop normally, have no obvious morphological defects, and are fertile. Despite the presence of the IRES-GFP cassette, analysis of several $L h x 6^{-}$heterozygotes killed at embryonic or postnatal stages showed no GFP expression in the forebrain or other cranial structures (data not shown). Genotyping of P0 animals from heterozygous intercrosses indicated that all expected genotypes (wt, $\operatorname{Lh} x 6^{+/-}$, and $\operatorname{Lh} x 6^{-/-}$) were represented at the expected Mendelian ratios. However, genotyping of 262 weaned offspring 
identified $96 \mathrm{wt}(36.6 \%)$ and $166 \mathrm{Lhx} \mathrm{6}^{+/-}$ (63.4\%) progeny but no $\operatorname{Lh} x 6^{-/-}$animals, indicating that homozygotes die before weaning. Indeed, during the first 2 weeks after birth, most $L h x 6^{-1-}$ animals failed to thrive, developed general weakness, and died shortly thereafter.

To examine the functional status of the Lhx $6^{-}$allele, we performed in situ hybridization on brain sections from embryos resulting from heterozygous intercrosses, using a riboprobe that includes the part of the transcription unit that has not been deleted. As expected, a large number of Lhx6-expressing cells were detected in sections from wild-type and heterozygous embryos but Lhx6-specific transcripts were absent from the ventral forebrain and the cortex of mutant embryos (Fig. $3 C, D)$. To further examine the ability of the $L h x 6^{-}$allele to encode a functional product, we immunostained brain sections from control and mutant embryos (E12.5 and E16.5) with polyclonal antisera specific for Lhx6 (Lavdas et al., 1999). A large number of Lhx6-positive nuclei were observed in the cortex and the ventral forebrain of wild-type and heterozygous animals, but virtually no signal was detectable in equivalent sections from mutant animals (Fig. 3E-H). Finally, Western blot analysis of protein extracts from the forebrain of wt and $L h x 6^{-/-}$embryos showed a dramatic reduction in the levels of Lhx6 (Fig. 3I). Together, these studies suggest that $\operatorname{Lhx} 6^{-}$represents a severe loss-offunction allele of $\operatorname{Lhx} 6$.
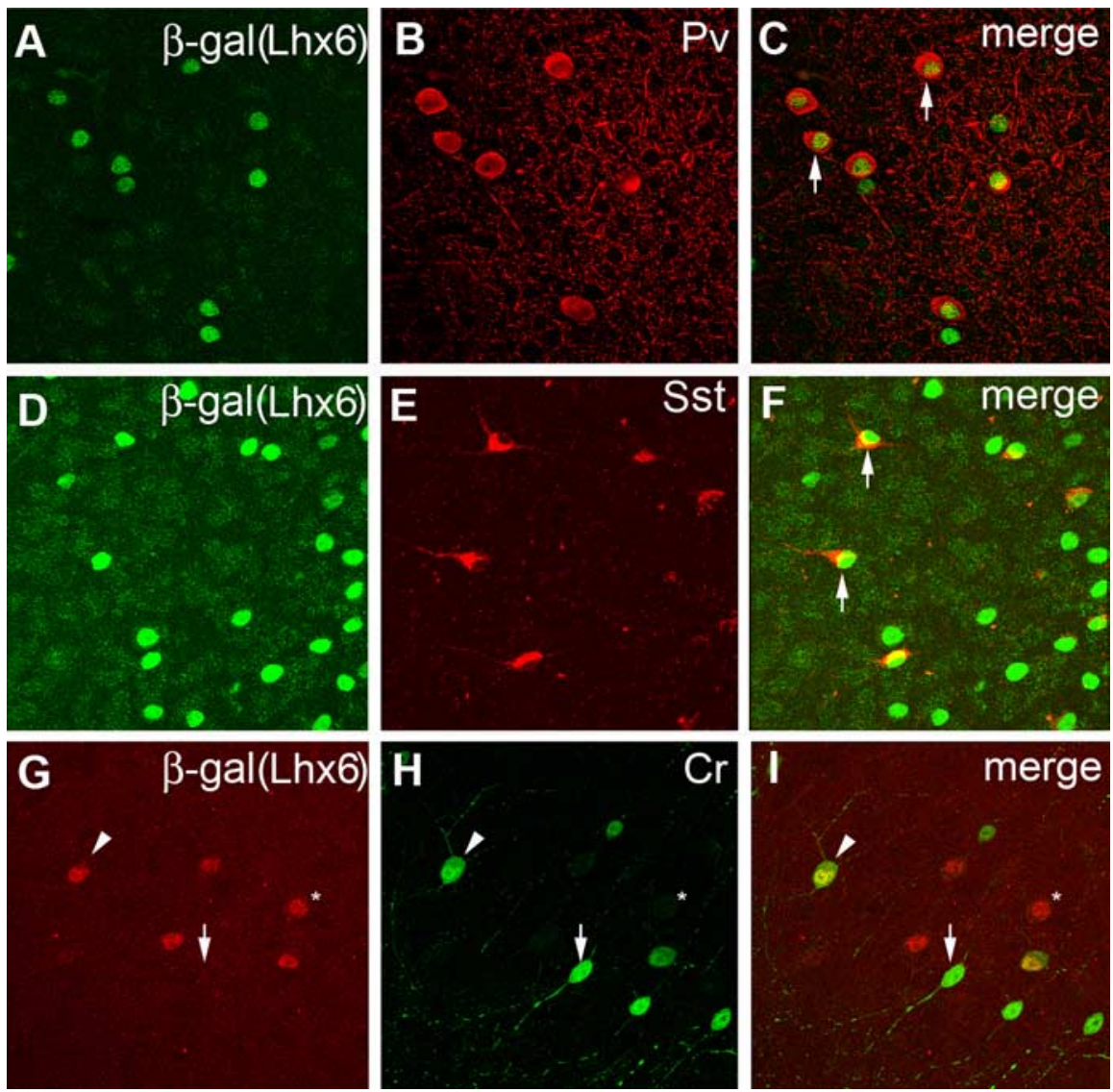

Figure 2. The majority of $\mathrm{Pv}^{+}$and $\mathrm{Sst}^{+}$cortical interneurons express $\mathrm{Lhx6}$. Confocal microscope images of cortical sections from $L h \times 6^{+/ \text {LacZins }}$ animals double immunostained for $\beta$-gal and either $\operatorname{Pv}(\boldsymbol{A}-\boldsymbol{C})$, or Sst $(\boldsymbol{D}-\boldsymbol{F}), \operatorname{or} \boldsymbol{C r}(\boldsymbol{G}-\boldsymbol{I})$. As is evident from the merged images, virtually all Pv-and Sst-expressing interneurons coexpress $\beta$-gal ( $\boldsymbol{C}, \boldsymbol{F}$, arrows). In contrast, $\beta$-gal was generally excluded from neurons of bipolar morphology that expressed high levels of $\mathrm{Cr}(\mathbf{G}-\mathbf{I}$, arrows). Colocalization of $\beta$-gal and $\mathrm{Cr}$ was observed in a subpopulation of neurons of variable morphology that expressed lower levels of $\mathrm{Cr}(\mathbf{G}-\mathbf{I}$, arrowheads). The asterisk (in $\mathbf{G}-\mathbf{I}$ ) indicates a representative cell that is positive for $\beta$-gal but negative for $C r$.

\section{Similar number but abnormal distribution of GABAergic interneurons in the cortex of $\mathrm{Lhx} 6^{-/-}$animals}

Brains of $L h \times 6^{-/-}$mice at P15 have normal gross morphology, whereas histological examination (hematoxylin and eosin or Nissl staining) did not reveal any obvious abnormalities (supplemental Fig. $1 A-D$, available at www.jneurosci.org as supplemental material). In addition, several lamination markers, such as Er81 and Cux2, show similar expression pattern between control and mutant animals (supplemental Fig. $1 E-H$, available at www. jneurosci.org as supplemental material), suggesting that deletion of Lhx6 does not result in profound changes of cortical lamination.

Because expression of $\operatorname{Lhx} 6$ in the cortex is restricted to GABAergic interneurons (Lavdas et al., 1999; Cobos et al., 2005, 2006), we examined the number and distribution of these cells in the cortex of 2- to 3-week-old $\operatorname{Lh} x 6^{-}$heterozygous and homozygous mice using a Gad1-specific riboprobe. We found that the number of GAD $67^{+}$cells present in the neocortex of control and Lhx6-deficient animals was similar $(284 \pm 10$ cells/unit area and $275 \pm 15$ cells/unit area, respectively; see Materials and Methods for definition of unit area) (Fig. 4A,B). Despite the similar number, the distribution of GAD6 ${ }^{+}$cells along the ventricular-pial axis was distinctly different between the two genotypes. In control animals, $\mathrm{GAD} 67^{+}$cells were distributed relatively uniformly, with a small tendency for interneurons to occupy the upper and middle cortical layers (Fig. $4 A$ ). In contrast, the majority of $\mathrm{GAD}^{+} 7^{+}$cells in $\operatorname{Lh} x 6^{-}$mutants accumulated in the upper or deeper layers, with the central layers being relatively free of Gad1expressing cells (Fig. 4B). Quantification of this effect in the motor and somatosensory cortex is shown in Figure 4, $C$ and $D$.

Similar to the neocortex, the hippocampus of $L h x 6^{-}$mutant animals showed no reduction in the number of GAD67 ${ }^{+}$cells (Fig. 4E,F). However, the distribution of Gad1-expressing cells in the hippocampal layers of mutant animals was altered relative to their heterozygous littermates. Thus, in $\operatorname{Lh} x 6^{+/-}$mice, $\sim 50 \%$ of the total GABAergic population in the CA1 area of hippocampus proper were located in the so and pcl. In $L h x 6^{-/-}$animals, however, the majority $(64 \%)$ of $\mathrm{GAD} 7^{+}$cells were found in the deep layers, namely the stratum radiatum ( $\mathrm{sr}$ ) and stratum lacunosum moleculare (slm) (Fig. 4E,F). In particular, we noticed that the number of $\mathrm{GAD} 67^{+}$cells present in the pcl of mutant animals $\left(13.1 \pm 0.6 \%\right.$ of total GAD $67^{+}$cell population) was significantly reduced relative to wild-type controls $(22.7 \pm 1.1 \%)$ (Fig. 4, compare $E$ and $F$ ). Together, our experiments show that deletion of $L h x 6$ does not prevent the expression of GABA, suggesting that this factor is not required for the specification of MGE-derived progenitors into GABAergic neurons. However, Lhx6 activity is required for the normal distribution of interneurons in the neocortex and the hippocampus. 

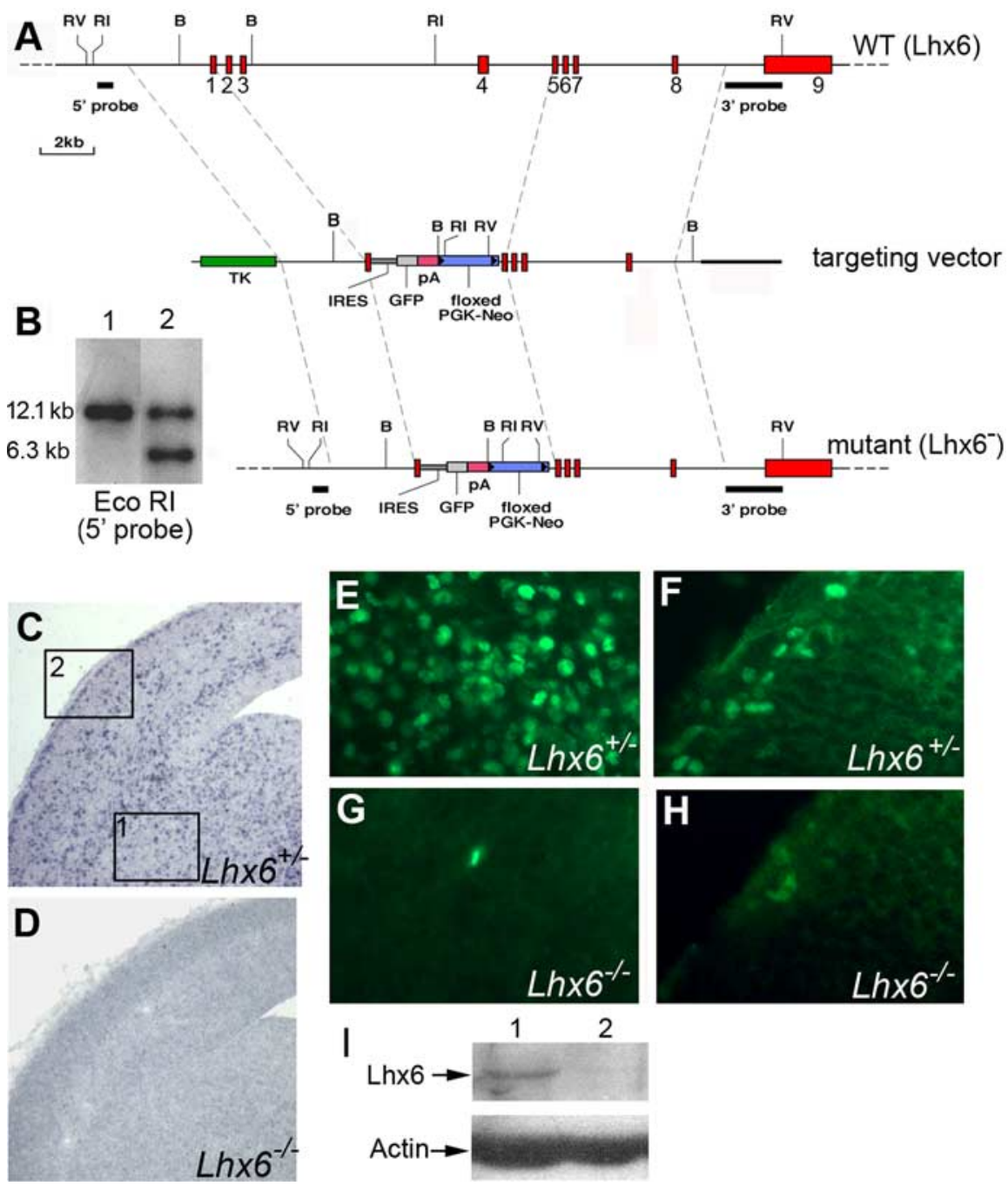

Figure 3. Targeting of the Lhx6 locus. A, Shown at the top is a diagrammatic representation of the Lhx6 locus. The middle diagram represents the targeting construct, whereas shown at the bottom is the mutant $L h x 6^{-}$allele. $B$, Southern blot analysis of EcoRI-digested genomic DNA from a wild-type (lane 1 ) and a heterozygous (lane 2) clone using the $5^{\prime}$ external probe (indicated in A). $\boldsymbol{C}, \boldsymbol{D}$, In situ hybridization on forebrain sections from E15.5 heterozygous $(\boldsymbol{C})$ and homozygous (D) Lhx $6^{-}$embryos with an Lhx6-specific riboprobe. $\boldsymbol{E}-\boldsymbol{H}$, Immunostaining of forebrain sections from E15.5 heterozygous $(\boldsymbol{E}, \boldsymbol{F})$ and homozygous $(\boldsymbol{G}, \boldsymbol{H})$ embryos with an Lhx6-specific polyclonal antiserum. Boxes 1 and 2 in $\mathbf{C}$ show the areas represented in $\boldsymbol{E}, \boldsymbol{G}$, and $\boldsymbol{F}, \boldsymbol{H}$, respectively. I, Western blot analysis of protein extracts from the forebrain of wild-type (lane 1) and $L h x 6^{-/-}$(lane 2) embryos. B, BamHl; RI, EcoRl; RV, EcoRV; TK, thymidine kinase; WT, wild type.

\section{Lhx6 is required primarily for the generation of the $\mathrm{Pv}^{+}$and} Sst ${ }^{+}$subpopulations of cortical interneurons

The expression of Lhx6 in specific subpopulations of cortical interneurons raised the possibility that this factor is required for the formation of certain neurochemical subtypes of GABAergic interneurons. To address this question, we compared the expression of $\mathrm{Pv}, \mathrm{Sst}$, and $\mathrm{Cr}$ in the cortex of animals heterozygous or homozygous for the $L h x 6^{-}$mutation. As expected, a large number of $\mathrm{Pv}^{+}$cells were detected in the neocortex of $\operatorname{Lhx} 6^{+/-}$animals. In contrast, Pv expression was drastically reduced in $L h x 6^{-}$ mutants (by $89.4 \pm 3.6 \%$ relative to $\mathrm{wt}$ ) with only few positive cells remaining mostly in the barrel cortex (Fig. $5 A, B$ ) (data not shown). A dramatic reduction of $\mathrm{Sst}^{+}$cells (by $93.0 \pm 0.6 \%$ ) was also observed in the cortex of $\operatorname{Lh} x 6^{-}$homozygous animals relative to heterozygous littermates (Fig. $5 C, D$ ). In contrast to these markers, $\mathrm{Cr}^{+}$cells were reduced to a lesser extent (by $37.7 \pm$ 9.6\%) in the neocortex of $L h x 6^{-}$mutants (Fig. $5 E, F$ ). However, we observed that the residual population of $\mathrm{Cr}^{+}$cells was clearly redistributed among the cortical layers of Lhx6-deficient animals. Thus, in control brain, the majority of $\mathrm{Cr}^{+}$cells were present in the upper cortical layers, but in Lh $x 6^{-}$mutants they were distributed equally between upper and lower cortical layers (Fig. 5, compare $E$ and $F$ ). The majority of $\mathrm{Cr}^{+ \text {high }}$ cells in $\operatorname{Lh} x 6^{+/-}$animals have the characteristic bipolar morphology with their axons arranged along the ventricular-pial axis (Fig. 5E, inset). Although a large number of $\mathrm{Cr}^{+}$high cells were observed in the cortex of $\operatorname{Lh} x 6^{-} \mathrm{mu}$ tants, very few of them showed the characteristic bipolar morphology that is normally associated with high levels of $\mathrm{Cr}$ expression (Fig. 5F, inset) (DeFelipe, 1993; Kubota et al., 1994; Porter et al., 1998; Butt et al., 2005).

Similar to the neocortex, we observed a dramatic reduction in the number of $\mathrm{Pv}^{+}$ and $\mathrm{Sst}^{+}$cells in the hippocampus of Lhx $6^{-}$mutant animals relative to controls (Fig. 6A-D). In contrast, the number or distribution of $\mathrm{Cr}^{+}$cells was similar between the two genotypes (Fig. 6E,F) $(29 \pm 2$ cells/unit area in control and $33 \pm$ 5 cells/unit area in mutants) (see Materials and Methods for definition of unit area). Together, these studies demonstrate that Lhx6 activity is necessary for the normal specification of distinct neurochemical subtypes of cortical interneurons.

\section{Delayed migration and abnormal} distribution of tangentially migrating cortical interneurons in Lhx6-deficient embryos

The majority of GABAergic interneurons of the neocortex and the hippocampus are born in the MGE and reach the dorsal telencephalon by tangential migration (Anderson et al., 1997; Pleasure et al., 2000; Metin et al., 2006). To examine the role of $L h x 6$ in the tangential migration of cortical interneurons in vivo, we analyzed the distribution of Gad1-expressing cells in the forebrain of $\operatorname{Lhx} 6^{+/-}$and $\operatorname{Lh} x 6^{-/-}$ embryos by in situ hybridization. In E13.5 Lhx $6^{+/-}$embryos, a large number of GAD67 ${ }^{+}$cells were detected in the MGE and LGE and in the MZ and the IZ/SVZ of the lateral cortex (Fig. 7A). Although equal intensity signal was observed in the ventral forebrain of $L h x 6^{-/-}$embryos, the front of tangentially migrating $\mathrm{GAD} 7^{+}$cells in the cortex was located at a more ventrolateral position, suggesting a delay in the migration of cortical interneuron progenitors in these embryos (Fig. $7 B$ ). Moreover, the allocation of $\mathrm{GAD}_{67}{ }^{+}$cells in the $\mathrm{MZ}$ and the IZ/SVZ of $\operatorname{Lh} x 6^{-/-}$ embryos was less clear relative to control brain (Fig. 7, compare $A$ and $B$ ). At later embryonic stages (E15.5), GAD67 ${ }^{+}$cells had populated the neocortex and most of the hippocampal anlage of heterozygous embryos (Fig. 7C). In the neocortex, GAD67 ${ }^{+}$cells were found mainly in the MZ and the IZ/SVZ, but by this stage numerous cells had also populated the cortical plate (Fig. 7C). In similar stage mutant embryos, most of $\mathrm{GAD}^{+} 7^{+}$cells were 
present in the IZ/SVZ, in a stream that extended well into the hippocampal anlage (Fig. 7D). However, most of the remaining cells were found at the subplate of the lateral cortex, with the $\mathrm{MZ}$ and the cortical plate containing very few $\mathrm{GAD}^{+}{ }^{+}$cells (Fig. 7D). These differences in the distribution of GABAergic interneurons were also confirmed using two additional markers of cortical interneurons, Dl 22 (Anderson et al., 1997; Stuhmer et al., 2002) and ErbB4 (Yau et al., 2003; Flames et al., 2004) (data not shown).

To explore in more detail the effect of the $L h x 6^{-}$mutation on the morphology and tangential migration of cortical interneuron progenitors, we generated animals heterozygous for the GAD67-GFP allele (Tanaka et al., 2003) and either heterozy-

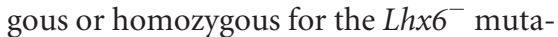
tion. In the brain of E12.5 $\operatorname{Lh} \times 6^{+/-}$; GAD67-GFP embryos, GFP ${ }^{+}$cells had crossed the corticostriatal boundary and entered the lateral part of the cortex, mostly via the $\mathrm{MZ}$ (Fig. $7 E$ ). In contrast, in similar stage $L h x 6^{-/-}$; GAD67-GFP embryos, very few $\mathrm{GFP}^{+}$cells were found in the cortex (including the MZ) (Fig. $7 F$ ). At E13.5, GFP ${ }^{+}$cells had colonized the lateral cortex of $L h \times 6^{+/-}$; GAD67-GFP embryos and were present mainly in the $\mathrm{MZ}$ and the IZ/SVZ (Fig. 7G). Relative to control embryos, fewer $\mathrm{GFP}^{+}$cells were found in the cortex of $L h \times 6^{-/-}$; GAD67GFP mutants at this stage (Fig. $7 H$ ). Moreover (and consistent with our in situ hybridization analysis) (Fig. 7C,D), the majority of $\mathrm{GFP}^{+}$cells were located in the IZ/SVZ, with very few cells present in the MZ of Lhx6-deficient embryos. Despite the differences in the spatial distribution of cortical interneurons, our analysis thus far has identified no dramatic morphological differences between $\mathrm{GFP}^{+}$ cells in the IZ/SVZ of $\operatorname{Lh} x 6^{+/-}$and $\operatorname{Lh} \times 6^{-1-}$ embryos (Fig. 7, compare high-magnification images of cells in the insets of $G$ and $H)$. These studies demonstrate that deletion of $\operatorname{Lh} x 6$ leads to a delay in the migration of cortical interneurons and alters their allocation into the appropriate migratory streams in the cortex. Unfortunately, because of an apparent genetic interaction between the GAD67-GFP and $L h x 6^{-}$alleles, we have been unable to compare later stages of embryogenesis, because the majority of Lhx $6^{-/-}$; GAD67-GFP embryos die in utero around E15.5.

To exclude the possibility that the migratory behavior of Lhx6-deficient cortical interneurons does not reflect changes in the expression of the molecular markers and reporter alleles used in our analysis, we compared the migration of DiI-labeled MGE cells in cultured brain slices from E13.5-E14.5 $\mathrm{Lh} \times 6^{+/-}$and Lh $x 6^{-/-}$embryos. Consistent with the origin of cortical interneurons from the MGE, fluorescent cells were detected in the cortex of heterozygous slices ( $n=46$, representing 8 E13.5 and 15 E14.5 embryos) maintained in culture for $48 \mathrm{~h}$ (supplemental Fig. $2 B$, available at www.jneurosci.org as supplemental material). In contrast, DiI-labeled cells were absent from the cortex of mutant slices ( $n=22$, representing 4 E13.5 and 7 E14.5 embryos) cultured in parallel (supplemental Fig. $2 C$, available at www.
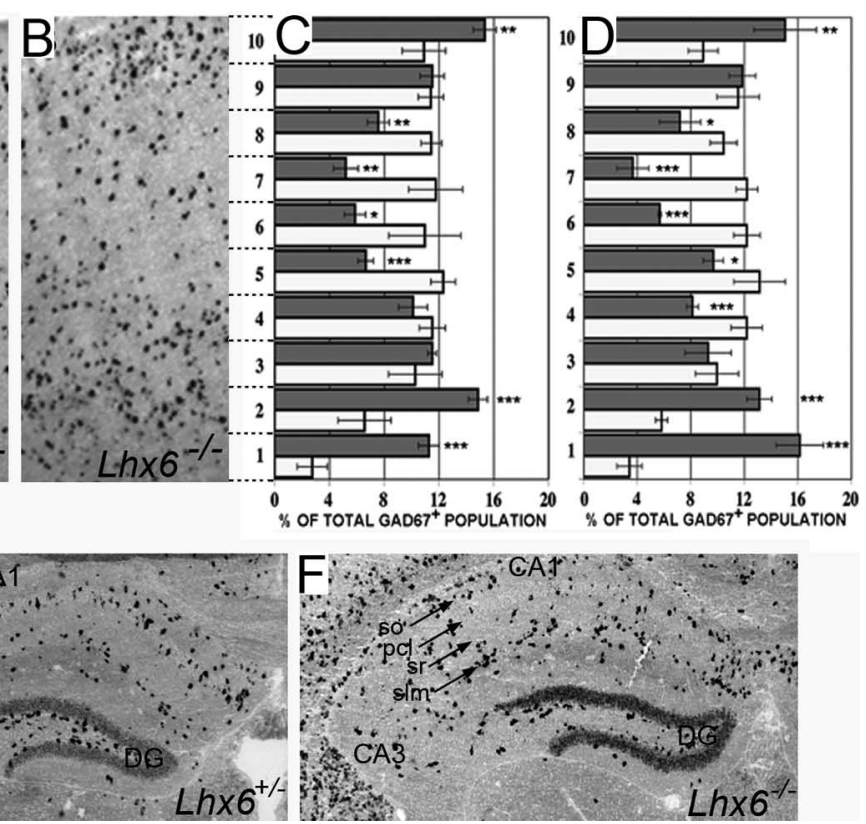

Lhx6

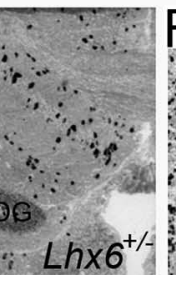

cells in the cortex of $L h x 6^{-}$mutants. Coronal brain sections from 2-week-old heterozygous $(\boldsymbol{A})$ or homozygous $(\boldsymbol{B})$ animals were hybridized with a Gad1-specific riboprobe. In contrast to wild-type sections, in which $\mathrm{GAD} 67^{+}$cells are distributed mostly uniformly, in mutant sections $\mathrm{GAD} 67^{+}$cells were mostly hetezygous and homozygous $\mathrm{Lhx6^{- }}$ animals were subdivided into 10 bins, and the proportion of GAD67 ${ }^{+}$cells present in each

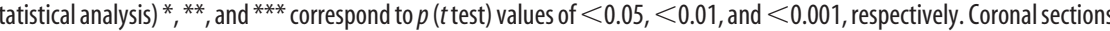
( cells is not reduced, but similar to the neocortex they appear to be redistributed in the hippocampal layers of the CA region. DG, Dentate gyrus; ISH, in situ hybridization; pcl, pyramidal cell layer; so, stratum oriens; slm, stratum lacunosum molecu-

jneurosci.org as supplemental material). Occasionally, fluorescent cells were found away from the DiI crystal in mutant slices but were restricted in the ventral forebrain (supplemental Fig. 2C, available at www.jneurosci.org as supplemental material). These findings support the idea that normal $L h x 6$ activity is required for the migration of the newly born GABAergic interneurons from the MGE.

To begin investigating whether the $\operatorname{Lhx6^{-}}$ mutation interferes with the normal tangential migration of cortical interneurons in a cell-autonomous manner, MGE explants from E13.5 Lhx6 heterozygous and homozygous embryos were cultured for $24 \mathrm{~h}$ in a three-dimensional collagen matrix. At the end of the culture period, the position of MGE-derived cells was assessed by nuclear [DAPI (4', $6^{\prime}$-diamidino-2-phenylindole)] staining or staining for Lhx6 and neuronal markers. Consistent with previous reports (Metin et al., 1997; Wichterle et al., 1999; Nery et al., 2002), MGE cells invaded profusely the surrounding collagen and migrated radially in all control explants analyzed $(100 \% ; n=15$, on average 4 explants were established from each embryo) (Fig. 8 B). Cell migration was also observed in MGE explants from Lhx6deficient embryos, but the front of radially migrating cells was always located closer to the explant (Fig. 8C) (194.51 $\pm 13.68 \mu \mathrm{m}$ for control and $141.40 \pm 6.91 \mu \mathrm{m}$ for mutant explants; $t$ test, $p<$ $0.005)$. This experiment suggests that the reduced tangential migration of cortical interneuron progenitors observed in $\operatorname{Lh} \times 6^{-}$ homozygous brain is attributable, at least partly, to an intrinsic migratory deficit of MGE-derived cells. 


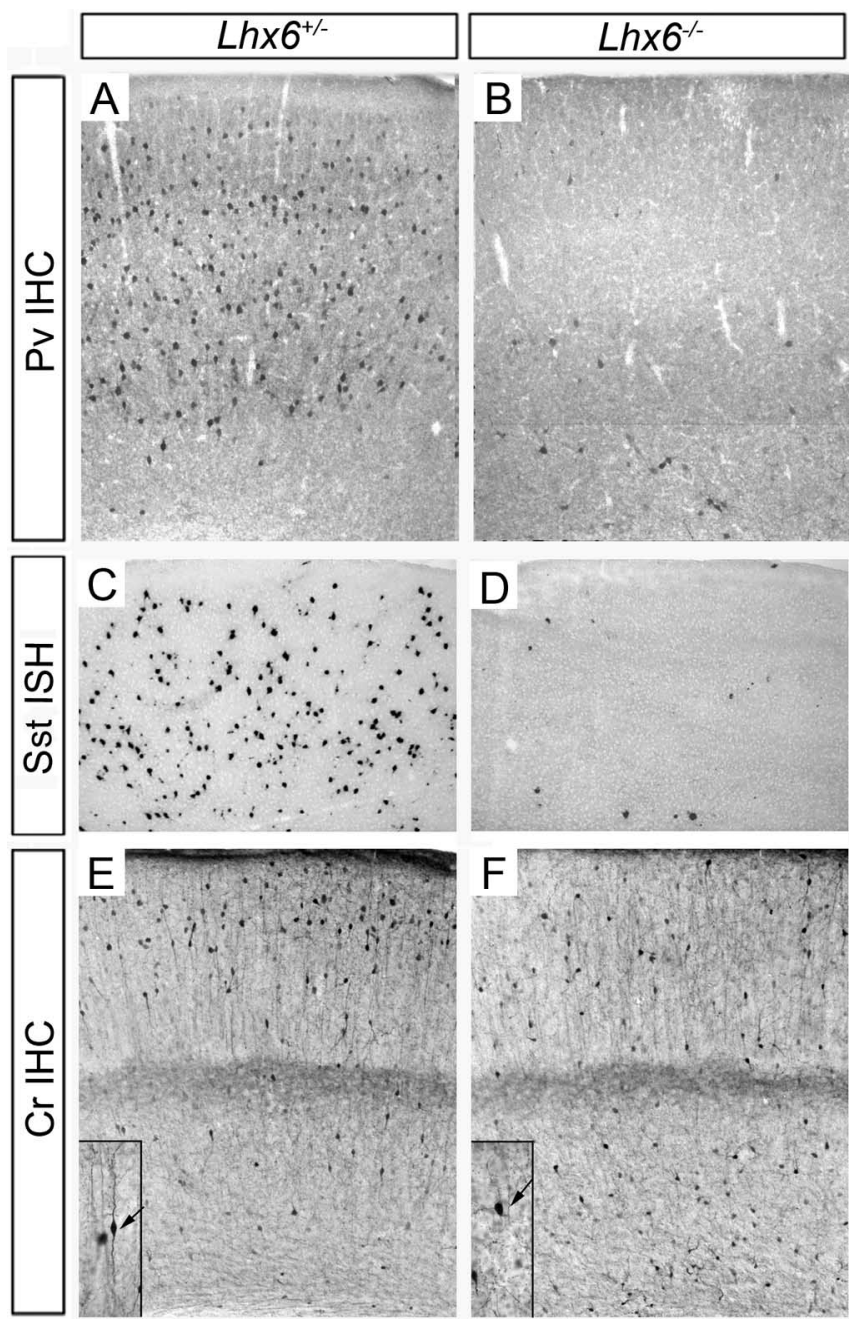

Figure 5. Severe reduction in the number of Pv- and Sst-expressing interneurons in the neocortex of $L h \times 6^{-}$mutants. Equivalent sections from the neocortex of 2-week-old animals heterozygous $(\boldsymbol{A}, \boldsymbol{C}, \boldsymbol{E})$ or homozygous $(\boldsymbol{B}, \boldsymbol{D}, \boldsymbol{F})$ for $L h x 6^{-}$were immunostained for $\operatorname{Pv}(\boldsymbol{A}, \boldsymbol{B})$ or $\operatorname{Cr}(\boldsymbol{E}, \boldsymbol{F})$ or hybridized with an Sst-specific riboprobe $(\boldsymbol{C}, \boldsymbol{D})$. The insets in $\boldsymbol{E}$ and $\boldsymbol{F}$ show high magnifications of representative $\mathrm{Cr}^{+}$neurons (arrows) of the corresponding genotypes. IHC, Immunohistochemistry; ISH, in situ hybridization.

\section{Discussion}

We demonstrate here that the LIM homeodomain factor Lhx6 is preferentially expressed in $\mathrm{Pv}^{+}$and $\mathrm{Sst}^{+}$cortical interneurons, but is absent from bipolar interneurons expressing high levels of Cr. By analyzing homozygous mutant mice, we show that $L h x 6$ is dispensable for GABAergic specification in the MGE, but its activity is required for the differentiation of MGE-derived progenitors into $\mathrm{Pv}$ - and Sst-expressing interneurons. The CGE-derived $\mathrm{Cr}^{+}$subpopulation of interneurons is affected to a lesser extent in Lh $x 6^{-/-}$animals. Lhx6 is also required for the normal pattern of migration of GABAergic interneurons during embryogenesis and for their allocation to the appropriate cortical layers in postnatal animals.

\section{Lhx6 controls the specification of $\mathrm{Pv}^{+}$and $\mathrm{Sst}^{+}$interneurons in the mammalian cortex}

Cobos et al. $(2005,2006)$ have recently reported that $79-94 \%$ of $\mathrm{Pv}^{+}, 55-68 \%$ of $\mathrm{Sst}^{+}$, and $2-5 \%$ of $\mathrm{Cr}^{+}$interneurons in the neocortex and the hippocampus express $L h x 6$. Our present findings support the high degree of coexpression of Pv and Lhx6, but
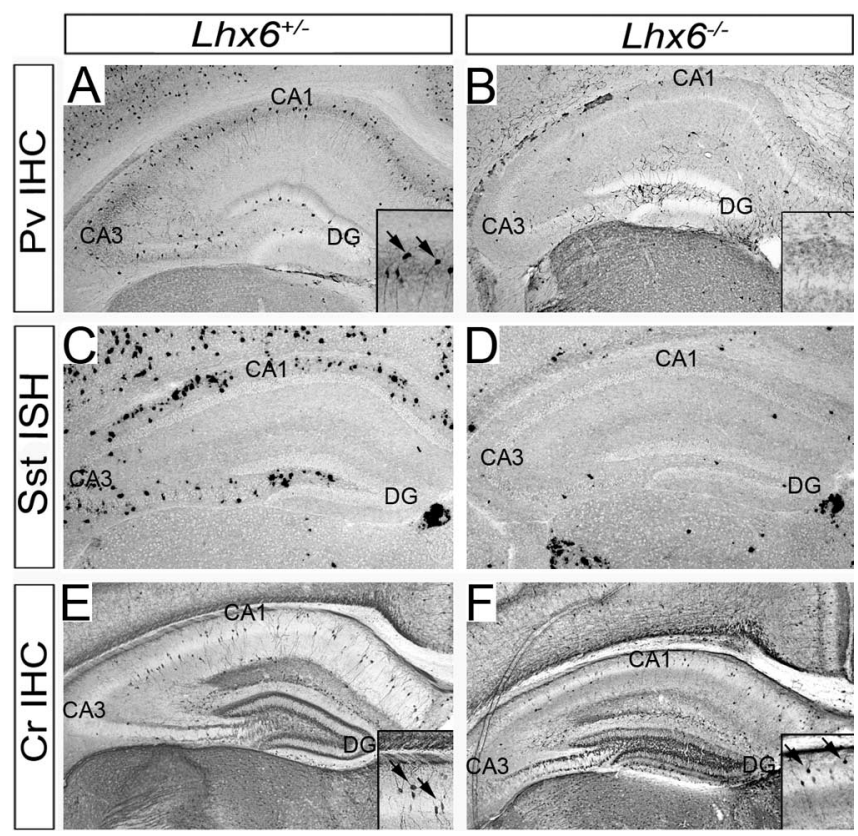

Figure 6. Severe reduction in the number of Pv- and Sst-expressing interneurons in the hippocampus of $L h \times 6^{-}$mutants. Equivalent sections from the hippocampus of 2-week-old animals heterozygous $(\boldsymbol{A}, \boldsymbol{C}, \boldsymbol{E})$ or homozygous $(\boldsymbol{B}, \boldsymbol{D}, \boldsymbol{F})$ for $L h \times 6^{-}$were immunostained for $\mathrm{Pv}$ $(\boldsymbol{A}, \boldsymbol{B}) \operatorname{or} \operatorname{Cr}(\boldsymbol{E}, \boldsymbol{F})$ or hybridized with an Sst-specific riboprobe $(\boldsymbol{C}, \boldsymbol{D})$. The insets in $\boldsymbol{A}, \boldsymbol{B}, \boldsymbol{E}$, and $\boldsymbol{F}$ show high magnification of areas corresponding to the CA1 region of the hippocampus. Note the dramatic reduction in the number of $\mathrm{Pv}^{+}$and Sst ${ }^{+}$cells in the hippocampus of Lhx6deficient animals. In contrast, the number of $\mathrm{Cr}^{+}$cells in the $\mathrm{CA} 1$ region of mutant animals is unaffected. The arrows in the insets indicate positive cells. DG, Dentate gyrus; IHC, immunohistochemistry; ISH, in situ hybridization.

contrary to the findings of Cobos et al., we demonstrate that $>95 \%$ of $\mathrm{Sst}^{+}$cortical neurons are also positive for Lhx6. In addition, we show that the proportion of $\mathrm{Cr}^{+}$cells that coexpress Lhx6 is $\sim 60 \%$. Despite these differences, our groups agree in that Lhx6 is preferentially expressed in Pv- and Sst-expressing subpopulations of cortical interneurons and that the $\mathrm{Cr}^{+ \text {high }}$ bipolar interneurons are negative for $\operatorname{Lh} x 6$. The restricted expression of Lhx6 in a subpopulation of cortical interneurons is consistent with our observation that in GAD67-GFP animals, only 75\% of $\mathrm{GFP}^{+}$cells coexpress Lhx6. Most likely, the Lhx6 ${ }^{-} \mathrm{GFP}^{+}$cells in the cortex of these animals represent the $\mathrm{Cr}^{+}$high subpopulation of cortical neurons, a suggestion supported by an independent estimation that $\sim 20 \%$ of cortical interneurons in rodents express high levels of $\mathrm{Cr}$ (Gonchar and Burkhalter, 1997). Coexpression of Lhx6 and Pv or Sst is also consistent with studies indicating that these subclasses of cortical interneurons are derived from the MGE, an area of the ventral telencephalon expressing high levels of $\operatorname{Lhx6}$ (Grigoriou et al., 1998; Nery et al., 2002; Butt et al., 2005), whereas $\mathrm{Cr}^{+}$bipolar interneurons originate in the $\operatorname{Lh} x 6$-negative CGE (Wichterle et al., 2001; Nery et al., 2002; Valcanis and Tan, 2003; Xu et al., 2003, 2004; Lopez-Bendito et al., 2004; Butt et al., 2005). It has been suggested that discrete genetic programs operating in subdomains of the ventral telencephalon control the generation of distinct interneuron subtypes (Wonders and Anderson, 2005). In support of this, animals deficient for Nkx2.1, an MGE-specific homeodomain protein, show a specific loss of $\mathrm{Pv}^{+}$ and Sst ${ }^{+}$interneurons (Marin et al., 2000; Anderson et al., 2001). Our current data identify Lhx6 as an additional component of the molecular mechanisms that specify $\mathrm{Pv}^{+}$and Sst ${ }^{+}$cortical interneurons in the MGE. Moreover, the overlapping expression of $N k x 2.1$ and Lhx6 in the MGE of wild-type embryos (Grigoriou et 

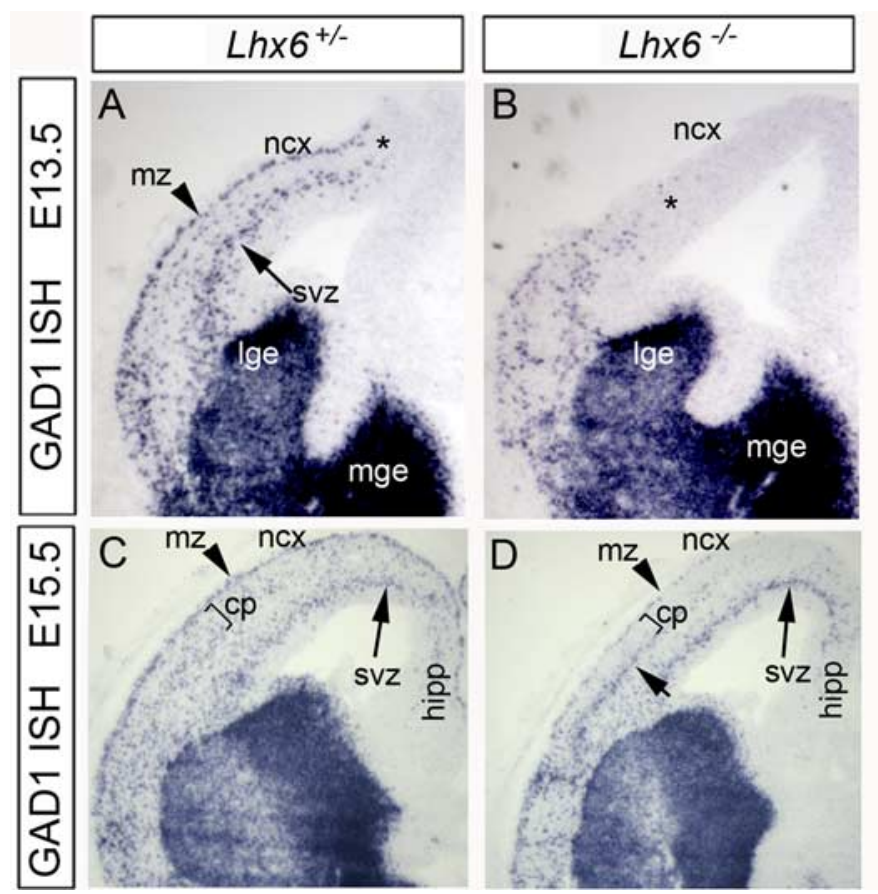
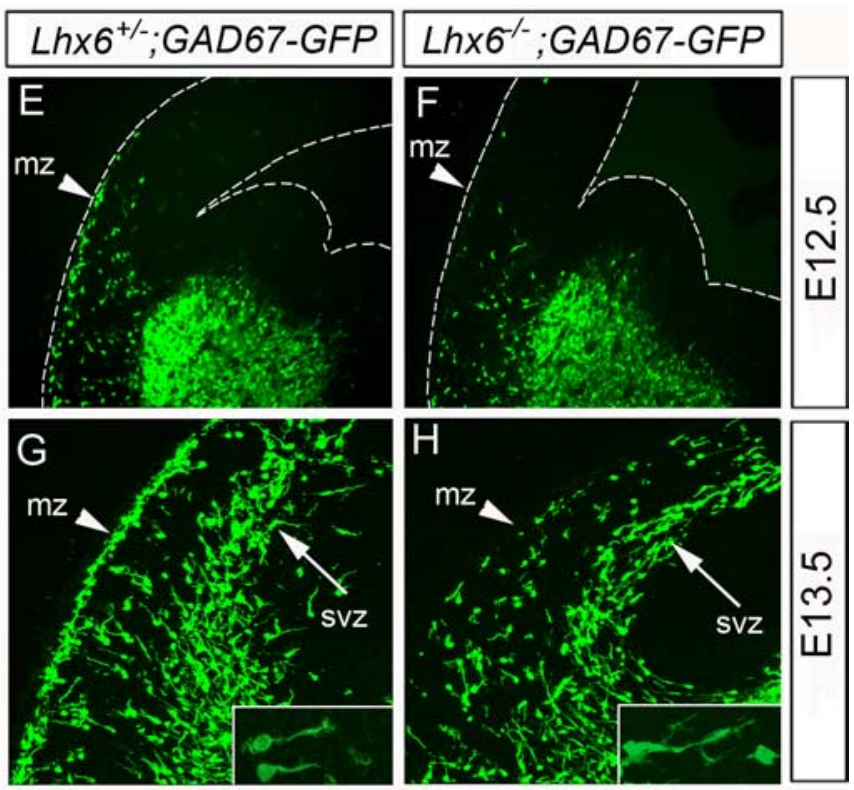

Figure 7. Delayed tangential migration and abnormal distribution of GABAergic interneurons in the cortex of $L h \times 6^{-}$mutant embryos. $A-D$, In situ hybridization of coronal brain sections from E13.5 $(\boldsymbol{A}, \boldsymbol{B})$ and E15.5 $(\boldsymbol{C}, \boldsymbol{D})$ embryos heterozygous $(\boldsymbol{A}, \boldsymbol{C})$ or homozygous $(\boldsymbol{B}, \boldsymbol{D})$ for the $L$ hx6 ${ }^{-}$mutation. Note that, relative to controls, in E13.5 mutant embry0s $\mathrm{GAD67}{ }^{+}$cells were restricted to the most ventrolateral cortex. In later-stage mutant embryos, $G A D 67^{+}$cells were found in the IZ/SVZ of the neocortex and the hippocampus but were drastically reduced in the MZ and the CP. Generation of heterozygous and homozygous $L h x 6^{-}$animals carrying the GAD67-GFP allele allowed us to use GFP as a reporter of tangentially migrating GABAergic interneurons. $\boldsymbol{E}-\boldsymbol{H}$, Immunostaining for GFP on coronal forebrain sections from E12.5 $(\boldsymbol{E}, \boldsymbol{F})$ or E13.5 $(\boldsymbol{G}, \boldsymbol{H})$ embryos heterozygous $(\boldsymbol{E}, \boldsymbol{G})$ or homozygous $(\boldsymbol{F}, \boldsymbol{H})$ for the $L_{h \times 6}{ }^{-}$mutation. Note the reduced number of GFP ${ }^{+}$cells crossing the corticostriatal boundary in $\mathrm{E} 12.5$ mutant embryos $(\boldsymbol{F})$ relative to controls $(\boldsymbol{E})$. In E13.5 mutant embryos $(\boldsymbol{H})$, the number of GFP ${ }^{+}$cells present in the MZ was reduced relative to control embryos $(\boldsymbol{G})$. No dramatic differences were observed in the morphology of tangentially migrating cells in the SVZ of control and Lhx6-deficient embryos (compare insets in $\boldsymbol{G}$ and $\boldsymbol{H}$ ). The arrowheads indicate the MZ, whereas the arrows point to the IZ/SVZ. The asterisks indicate the front of tangentially migrating interneurons. cp, Cortical plate; hipp, hippocampus; ISH, in situ hybridization; Ige, lateral ganglionic eminence, mge, medial ganglionic eminence; mz, marginal zone; ncx, neocortex; svz, subventricular zone.

al., 1998; Sussel et al., 1999; Nery et al., 2002), the loss of Lhx6 transcripts from the ventral forebrain of Nkx2.1-deficient animals (Sussel et al., 1999), and the similar phenotypic effects of the $L h x 6^{-}$and $N k \times 2.1^{-}$mutations on interneuron differentiation (Marin et al., 2000; Pleasure et al., 2000; Anderson et al., 2001) suggest that the two factors are components of a common regulatory cascade that controls the specification of GABAergic subtypes.

During embryogenesis, progenitors in the germinal zones of the subpallium generate "proto-GABAergic" neurons, which express the GABA-synthesizing genes Gad1 and Gad2 but lack molecular markers (such as $\mathrm{Pv}$ and $\mathrm{Cr}$ ) and electrophysiological properties characteristic of mature cortical interneurons (Alcantara et al., 1996; Flames and Marin, 2005; Wonders and Anderson, 2005). Despite the profound effect of the $\operatorname{Lhx} 6^{-} \mathrm{mu}-$ tation on the specification of $\mathrm{Pv}^{+}$and $\mathrm{Sst}^{+}$interneurons, the differentiation of Lhx6-deficient MGE progenitors into GABA ${ }^{+}$ neurons appeared normal. Thus, induction of Gad1 in the MGE of $L h x 6^{-1-}$ embryos was unaffected, whereas the final number of GAD67 ${ }^{+}$cells in the cortex of 2- to 3-week-old mutant animals was similar to that of control littermates. These observations suggest that Lhx6 is not required for GABAergic differentiation of MGE progenitors but has a critical role in their subtype specification. The mechanisms by which Lhx6 controls the subtype
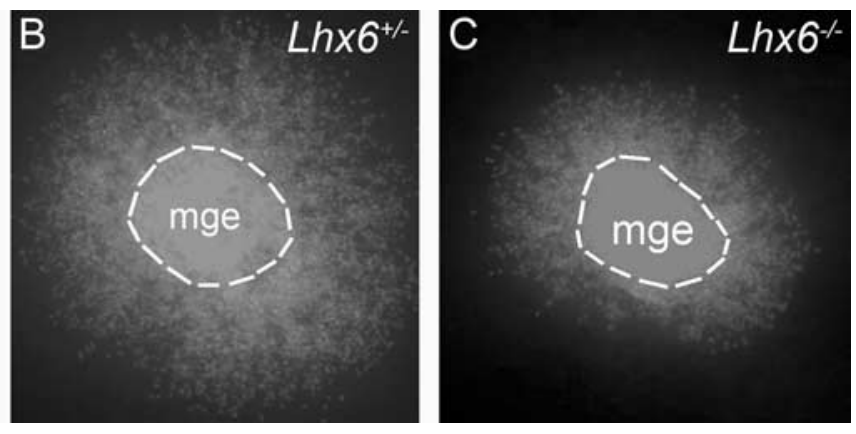

Figure 8. Intrinsic migratory deficit of Lhx6-deficient MGE cells. $A$, Schematic presentation of the area of the subpallium used for the MGE explant cultures. MGE explants from E13.5 heterozygous $(\boldsymbol{B})$ embryos show profuse migration into the collagen gel matrix. In contrast, reduced radial migration of MGE cells was observed in parallel cultures from $\mathrm{LhX6}^{-}$mutant embryos (C). The black box in $\boldsymbol{A}$ shows the area used to generate the MGE explants. mge, Medial ganglionic eminence; ncx, neocortex.

specification of GABAergic interneurons are currently unclear. Maturation of proto-GABAergic interneurons could be controlled by epigenetic signals produced by the microenvironment of the cortex. Alternatively, the various subtypes of cortical interneurons could be specified much earlier and before their arrival at the dorsal telencephalon by a unique combination of transcription factors acting in segregated pools of dividing progenitors or their postmitotic progeny (Flames and Marin, 2005). The transient delay in the tangential migration of $L h x 6^{-/-}$cortical interneurons and their abnormal distribution in embryonic and postnatal cortex, could indicate that the observed specification deficit of this lineage is secondary to the failure of GABAergic interneuron progenitors to encounter the appropriate signals in the cor- 
tical microenvironment. However, this hypothesis is unlikely to provide a satisfactory explanation for the specification deficits observed in $L h x 6^{-}$mutants for a number of reasons. First, dissociated MGE progenitors are capable of generating PV- and Sstexpressing neurons when maintained in culture (Xu et al., 2004). Second, a similar cell population when transplanted directly into the cortex of newborn mice, differentiates into mature GABAergic neurons expressing appropriate specification markers (Wichterle et al., 1999; Cobos et al., 2005). Finally, and consistent with our observations in the cortex, $\operatorname{Lh} x 6$ also controls the specification $\mathrm{Pv}^{+}$and $\mathrm{Sst}^{+}$interneurons in the ventral forebrain (such as the striatum) (our unpublished data). Therefore, the specification effect of Lhx6 on cortical interneurons is most likely independent of the particular migratory routes used by MGE cells to reach the cortex and the instructive influence of the cortical microenvironment. Moreover, the induction of Lhx6 during or shortly after the exit of MGE progenitors from the cell cycle (M. Denaxa, A. Achimastou, and V. Pachnis, unpublished observations) is consistent with the idea that the specification program of cortical interneurons is set up early and before their arrival at the dorsal telencephalon. In support of this, ultrasound-guided in utero transplantation of MGE- and CGE-derived progenitors has shown that the spatiotemporal coordinates of the origin of interneuron progenitors determine to a large extent their morphological, molecular, and physiological properties (Wichterle et al., 2001; Nery et al., 2002; Valcanis and Tan, 2003; Butt et al., 2005).

Mutations that preferentially affect the generation of specific subtypes of cortical interneurons have been described previously. Thus, deletion of the locus encoding urokinase plasminogen activator ( $\mathrm{uPA}$ ), a protease required for the efficient processing of the inactive pro-hepatocyte growth factor (HGF), results in almost complete loss of $\mathrm{Pv}^{+}$neurons in certain cortical areas without a significant change in the total number of interneurons (Powell et al., 2003; Levitt et al., 2004). The mechanism by which uPA controls the development of cortical interneurons is presently unclear, but it appears that appropriate maturation of HGF and activation of its receptor Met are necessary for the normal migration and differentiation of distinct interneuron groups (Powell et al., 2001). More recently, expression analysis of the $D l x 1$ homeobox gene showed preferential expression in Sst- and Cr-expressing subpopulations of cortical interneurons in postnatal mice. Moreover, analysis of Dlx1-deficient mice revealed a specific and progressive reduction in the population of Sst ${ }^{+}$and $\mathrm{Cr}^{+}$cortical interneurons, which was attributed to apoptotic cell death (Cobos et al., 2005). Although the molecular and cellular mechanisms by which genes such as $L h x 6, D l x 1$, and $u P A$ control the formation of interneurons subtypes appear to be distinct, these findings suggest that the interplay between extracellular signals and transcription factors is necessary for the establishment of functional interneuron circuits in the mammalian cortex.

In addition to the Pv- and Sst-expressing GABAergic interneurons, the MGE gives rise to other classes of neurons, such as the cholinergic interneurons of the striatum and cholinergic projection neurons of the ventral forebrain (Marin et al., 2000). Interestingly, differentiation of both types of forebrain cholinergic neurons requires $\operatorname{Lh} x 7$, a gene closely related to $\operatorname{Lh} x 6$ (Zhao et al., 2003; Mori et al., 2004; Fragkouli et al., 2005). Induction of Lhx6 and $L h x 7$ is dependent on expression of $\mathrm{Nkx} 2.1$, a homeodomain transcription factor that specifies the MGE and is necessary for normal formation of cortical and striatal interneurons (Sussel et al., 1999; Marin et al., 2000). It appears therefore that neuronal specification in the ventral forebrain follows rules similar to those operating in other parts of the CNS, such as the ventral spinal cord. In this region, graded signaling by morphogenetic proteins, such as Shh, defines specific domains of the ventricular zone, the progeny of which express unique combinations of homeodomain proteins, including LIM homeodomain factors that specify the identities of the emerging postmitotic neurons (Shirasaki and Pfaff, 2002). The requirement of $\operatorname{Lhx} 6$ and $\operatorname{Lhx} 7$ activity for the generation of cholinergic neurons and specific subpopulations of GABAergic interneurons suggests that a similar combinatorial code of LIM homeodomain transcription factors operates to specify distinct classes of neurons generated in the ventral forebrain. Understanding the molecular interactions and the nature of the putative transcriptional complexes in which Lhx6 and Lhx7 participate will further our molecular understanding of neuronal subtype specification in the mammalian brain.

\section{Lhx 6 controls the tangential migration of cortical interneurons during embryogenesis}

Previous studies have shown that reduced levels of Lhx6 in cultured embryonic brain slices impede the migration of GABAergic interneurons (Alifragis et al., 2004). Our studies extend these findings by demonstrating that $\operatorname{Lh} x 6$ activity is required in vivo at multiple stages of the colonization of the cortex by MGE-derived interneuron progenitors. Thus, in addition to their delay in arriving at and crossing the corticostriatal boundary, Lhx6deficient GABAergic cells fail to be distributed to the appropriate cortical domains during embryogenesis. In particular, we have observed a dramatic reduction in the number of $\mathrm{GABA}^{+}$cells in the MZ and the cortical plate of Lhx6-deficient embryos. Colonization of the cortical plate is critical for layer acquisition by cortical interneurons and is achieved during embryogenesis by $\mathrm{GABA}^{+}$cells in the MZ and the IZ/SVZ that change their mode of migration from tangential to radial (Metin et al., 2006). The paucity of Gad1-expressing cells in the cortical plate of $L h x 6^{-/-}$embryos is likely to result from reduced contribution from the $\mathrm{GABA}^{+}$cell populations in both the $\mathrm{MZ}$ and the IZ/SVZ and suggests that, in addition to its role in tangential migration (Alifragis et al., 2004; this study), Lhx6 also controls the radial migration of cortical interneurons during embryogenesis. It is well established that normal radial migration of the principal projection neurons is crucial for their correct laminar arrangement in the cortex (Kriegstein and Noctor, 2004). Interestingly, our analysis thus far has revealed no dramatic changes in the cortical lamination in $L h x 6^{-/-}$animals, suggesting that distinct molecular mechanisms regulate layer acquisition by cortical interneurons and projection neurons. Future experiments will be necessary to address whether and how the migratory deficits observed during embryogenesis are related to the abnormal distribution of cortical interneurons in the cortex of $\operatorname{Lh} x 6^{-}$mutants.

The early migratory defect of Lhx6-deficient GABAergic cells appears to be intrinsic to the tangentially migrating progenitors because it is reproduced in isolated MGE explants established from mutant embryos. Prominent migratory capacity is a hallmark of MGE-derived cells and a distinguishing characteristic of this region relative to other areas of the ventral forebrain, such as the LGE. The predominant expression of Lhx6 in postmitotic cells together with the normal expression of $N k x 2.1$ in the ventral forebrain of $\operatorname{Lhx} 6^{-}$mutant embryos (P. Liodis and V. Pachnis, unpublished observations) argue against the possibility that deletion of $\operatorname{Lh} x 6$ respecifies the MGE into an LGE-like structure. Instead, our findings argue that $\operatorname{Lh} x 6$ is required for the full expression of the migratory phenotype of MGE cells. It is currently unclear whether the two aspects of the "cortical interneuron pro- 
gram" that are dependent on Lhx6, namely, subtype specification and cell migration, are controlled independently by this factor or whether the migratory deficits and abnormal location of Lhx6deficient MGE-derived cells simply reflect their misspecification. Finally, it is possible that aspects of the migratory deficits of cortical GABAergic interneurons in Lhx6-deficient animals are attributable to non-cell-autonomous actions of the $L h x 6^{-}$mutation. This is more likely to be the case at later stages of corticogenesis, when subpopulations of $\mathrm{GABA}^{+}$cells allocated to spatially distinct cortical areas could influence the cytoskeletal organization and motility of other groups of interneurons. In support of such non-cell-autonomous effects, we have observed that Lhx6-negative $\mathrm{Cr}^{+}$high interneurons show characteristic changes in their pattern of axonal morphology and organization. The systematic analysis of cell-autonomous and non-cellautonomous effects of the $L h x 6^{-}$mutation will require the generation of chimeric animals with cortices composed of a mixture of wild-type and mutant cells.

\section{References}

Alcantara S, Soriano E, Ferrer I (1996) Thalamic and basal forebrain afferents modulate the development of parvalbumin and calbindin D28k immunoreactivity in the barrel cortex of the rat. Eur J Neurosci 8:1522-1534.

Alifragis P, Liapi A, Parnavelas JG (2004) Lhx6 regulates the migration of cortical interneurons from the ventral telencephalon but does not specify their GABA phenotype. J Neurosci 24:5643-5648.

Anderson SA, Eisenstat DD, Shi L, Rubenstein JL (1997) Interneuron migration from basal forebrain to neocortex: dependence on Dlx genes. Science 278:474-476.

Anderson SA, Marin O, Horn C, Jennings K, Rubenstein JL (2001) Distinct cortical migrations from the medial and lateral ganglionic eminences. Development 128:353-363.

Ang Jr ES, Haydar TF, Gluncic V, Rakic P (2003) Four-dimensional migratory coordinates of GABAergic interneurons in the developing mouse cortex. J Neurosci 23:5805-5815.

Ben-Ari Y, Holmes GL (2005) The multiple facets of gamma-aminobutyric acid dysfunction in epilepsy. Curr Opin Neurol 18:141-145.

Bulfone A, Puelles L, Porteus MH, Frohman MA, Martin GR, Rubenstein JL (1993) Spatially restricted expression of Dlx-1, Dlx-2 (Tes-1), Gbx-2, and Wnt-3 in the embryonic day 12.5 mouse forebrain defines potential transverse and longitudinal segmental boundaries. J Neurosci 13:3155-3172.

Butt SJ, Fuccillo M, Nery S, Noctor S, Kriegstein A, Corbin JG, Fishell G (2005) The temporal and spatial origins of cortical interneurons predict their physiological subtype. Neuron 48:591-604.

Casarosa S, Fode C, Guillemot F (1999) Mash1 regulates neurogenesis in the ventral telencephalon. Development 126:525-534.

Choi GB, Dong HW, Murphy AJ, Valenzuela DM, Yancopoulos GD, Swanson LW, Anderson DJ (2005) Lhx6 delineates a pathway mediating innate reproductive behaviors from the amygdala to the hypothalamus. Neuron 46:647-660.

Cobos I, Calcagnotto ME, Vilaythong AJ, Thwin MT, Noebels JL, Baraban SC, Rubenstein JL (2005) Mice lacking Dlx1 show subtype-specific loss of interneurons, reduced inhibition and epilepsy. Nat Neurosci 8:1059-1068

Cobos I, Long JE, Thwin MT, Rubenstein JL (2006) Cellular patterns of transcription factor expression in developing cortical interneurons. Cereb Cortex 16:i82-i88.

Corbin JG, Nery S, Fishell G (2001) Telencephalic cells take a tangent: nonradial migration in the mammalian forebrain. Nat Neurosci 4:1177-1182.

de Carlos JA, Lopez-Mascaraque L, Valverde F (1996) Dynamics of cell migration from the lateral ganglionic eminence in the rat. J Neurosci 16:6146-6156.

DeFelipe J (1993) Neocortical neuronal diversity: chemical heterogeneity revealed by colocalization studies of classic neurotransmitters, neuropeptides, calcium-binding proteins, and cell surface molecules. Cereb Cortex 3:273-289.

Denaxa M, Chan CH, Schachner M, Parnavelas JG, Karagogeos D (2001) The adhesion molecule TAG-1 mediates the migration of cortical inter- neurons from the ganglionic eminence along the corticofugal fiber system. Development 128:4635-4644.

Erlander MG, Tillakaratne NJ, Feldblum S, Patel N, Tobin AJ (1991) Two genes encode distinct glutamate decarboxylases. Neuron 7:91-100.

Flames N, Marin O (2005) Developmental mechanisms underlying the generation of cortical interneuron diversity. Neuron 46:377-381.

Flames N, Long JE, Garratt AN, Fischer TM, Gassmann M, Birchmeier C, Lai C, Rubenstein JL, Marin O (2004) Short- and long-range attraction of cortical GABAergic interneurons by neuregulin-1. Neuron 44:251-261.

Fragkouli A, Hearn C, Errington M, Cooke S, Grigoriou M, Bliss T, Stylianopoulou F, Pachnis V (2005) Loss of forebrain cholinergic neurons and impairment in spatial learning and memory in LHX7-deficient mice. Eur J Neurosci 21:2923-2938.

Gonchar Y, Burkhalter A (1997) Three distinct families of GABAergic neurons in rat visual cortex. Cereb Cortex 7:347-358.

Grigoriou M, Tucker AS, Sharpe PT, Pachnis V (1998) Expression and regulation of Lhx6 and Lhx7, a novel subfamily of LIM homeodomain encoding genes, suggests a role in mammalian head development. Development 125:2063-2074.

Hobert O, Westphal H (2000) Functions of LIM-homeobox genes. Trends Genet 16:75-83.

Jimenez D, Lopez-Mascaraque LM, Valverde F, De Carlos JA (2002) Tangential migration in neocortical development. Dev Biol 244:155-169.

Kawaguchi Y, Kubota Y (1997) GABAergic cell subtypes and their synaptic connections in rat frontal cortex. Cereb Cortex 7:476-486.

Kimura N, Ueno M, Nakashima K, Taga T (1999) A brain region-specific gene product Lhx6.1 interacts with Ldb1 through tandem LIM-domains. J Biochem (Tokyo) 126:180-187.

Kitanaka J, Takemura M, Matsumoto K, Mori T, Wanaka A (1998) Structure and chromosomal localization of a murine LIM/homeobox gene, Lhx8. Genomics 49:307-309.

Kriegstein AR, Noctor SC (2004) Patterns of neuronal migration in the embryonic cortex. Trends Neurosci 27:392-399.

Kubota Y, Hattori R, Yui Y (1994) Three distinct subpopulations of GABAergic neurons in rat frontal agranular cortex. Brain Res 649:159-173.

Lavdas AA, Grigoriou M, Pachnis V, Parnavelas JG (1999) The medial ganglionic eminence gives rise to a population of early neurons in the developing cerebral cortex. J Neurosci 19:7881-7888.

Legaz I, Garcia-Lopez M, Medina L (2005) Subpallial origin of part of the calbindin-positive neurons of the claustral complex and piriform cortex. Brain Res Bull 66:470-474.

Levitt P, Eagleson KL, Powell EM (2004) Regulation of neocortical interneuron development and the implications for neurodevelopmental disorders. Trends Neurosci 27:400-406.

Lopez-Bendito G, Sturgess K, Erdelyi F, Szabo G, Molnar Z, Paulsen O (2004) Preferential origin and layer destination of GAD65-GFP cortical interneurons. Cereb Cortex 14:1122-1133.

Marin O, Rubenstein JL (2003) Cell migration in the forebrain. Annu Rev Neurosci 26:441-483.

Marin O, Anderson SA, Rubenstein JL (2000) Origin and molecular specification of striatal interneurons. J Neurosci 20:6063-6076.

Markram H, Toledo-Rodriguez M, Wang Y, Gupta A, Silberberg G, Wu C, Monyer H (2004) Interneurons of the neocortical inhibitory system. Nat Rev Neurosci 5:793-807.

Matsumoto K, Tanaka T, Furuyama T, Kashihara Y, Mori T, Ishii N, Kitanaka J, Takemura M, Tohyama M, Wanaka A (1996) L3, a novel murine LIMhomeodomain transcription factor expressed in the ventral telencephalon and the mesenchyme surrounding the oral cavity. Neurosci Lett 204:113-116.

Metin C, Deleglise D, Serafini T, Kennedy TE, Tessier-Lavigne M (1997) A role for netrin-1 in the guidance of cortical efferents. Development 124:5063-5074.

Metin C, Baudoin JP, Rakic S, Parnavelas JG (2006) Cell and molecular mechanisms involved in the migration of cortical interneurons. Eur J Neurosci 23:894-900.

Mori T, Yuxing Z, Takaki H, Takeuchi M, Iseki K, Hagino S, Kitanaka J, Takemura M, Misawa H, Ikawa M, Okabe M, Wanaka A (2004) The LIM homeobox gene, L3/Lhx8, is necessary for proper development of basal forebrain cholinergic neurons. Eur J Neurosci 19:3129-3141.

Nadarajah B, Parnavelas JG (2002) Modes of neuronal migration in the developing cerebral cortex. Nat Rev Neurosci 3:423-432. 
Nadarajah B, Alifragis P, Wong RO, Parnavelas JG (2002) Ventricledirected migration in the developing cerebral cortex. Nat Neurosci 5:218-224.

Natarajan D, Marcos-Gutierrez C, Pachnis V, De Graaff E (2002) Requirement of signalling by receptor tyrosine kinase RET for the directed migration of enteric nervous system progenitor cells during mammalian embryogenesis. Development 129:5151-5160.

Nery S, Fishell G, Corbin JG, Wichterle H, Turnbull DH, Alvarez-Buylla A (2002) The caudal ganglionic eminence is a source of distinct cortical and subcortical cell populations. Nat Neurosci 5:1279-1287.

O'Gorman S, Dagenais NA, Qian M, Marchuk Y (1997) Protamine-Cre recombinase transgenes efficiently recombine target sequences in the male germ line of mice, but not in embryonic stem cells. Proc Natl Acad Sci USA 94:14602-14607.

Paxinos G, Franklin KBJ (2001) The mouse brain in stereotaxic coordinates, Ed 2. New York: Academic.

Pleasure SJ, Anderson S, Hevner R, Bagri A, Marin O, Lowenstein DH, Rubenstein JL (2000) Cell migration from the ganglionic eminences is required for the development of hippocampal GABAergic interneurons. Neuron 28:727-740.

Porter JT, Cauli B, Staiger JF, Lambolez B, Rossier J, Audinat E (1998) Properties of bipolar VIPergic interneurons and their excitation by pyramidal neurons in the rat neocortex. Eur J Neurosci 10:3617-3628.

Powell EM, Mars WM, Levitt P (2001) Hepatocyte growth factor/scatter factor is a motogen for interneurons migrating from the ventral to dorsal telencephalon. Neuron 30:79-89.

Powell EM, Campbell DB, Stanwood GD, Davis C, Noebels JL, Levitt P (2003) Genetic disruption of cortical interneuron development causes region- and GABA cell type-specific deficits, epilepsy, and behavioral dysfunction. J Neurosci 23:622-631.

Ramon y Cajal S (1911) Histology of the nervous system. New York: Oxford UP.

Schaeren-Wiemers N, Gerfin-Moser A (1993) A single protocol to detect transcripts of various types and expression levels in neural tissue and cultured cells: in situ hybridization using digoxigenin-labelled cRNA probes. Histochemistry 100:431-440.

Shirasaki R, Pfaff SL (2002) Transcriptional codes and the control of neuronal identity. Annu Rev Neurosci 25:251-281.

Somogyi P, Klausberger T (2005) Defined types of cortical interneurone structure space and spike timing in the hippocampus. J Physiol (Lond) 562:9-26.

Stuhmer T, Puelles L, Ekker M, Rubenstein JL (2002) Expression from a Dlx gene enhancer marks adult mouse cortical GABAergic neurons. Cereb Cortex 12:75-85.

Sussel L, Marin O, Kimura S, Rubenstein JL (1999) Loss of Nkx2.1 ho- meobox gene function results in a ventral to dorsal molecular respecification within the basal telencephalon: evidence for a transformation of the pallidum into the striatum. Development 126:3359-3370.

Tamamaki N, Fujimori KE, Takauji R (1997) Origin and route of tangentially migrating neurons in the developing neocortical intermediate zone. J Neurosci 17:8313-8323.

Tanaka D, Nakaya Y, Yanagawa Y, Obata K, Murakami F (2003) Multimodal tangential migration of neocortical GABAergic neurons independent of GPI-anchored proteins. Development 130:5803-5813.

Tanaka DH, Maekawa K, Yanagawa Y, Obata K, Murakami F (2006) Multidirectional and multizonal tangential migration of GABAergic interneurons in the developing cerebral cortex. Development 133:2167-2176.

Valcanis H, Tan SS (2003) Layer specification of transplanted interneurons in developing mouse neocortex. J Neurosci 23:5113-5122.

Whittington MA, Traub RD (2003) Interneuron diversity series: inhibitory interneurons and network oscillations in vitro. Trends Neurosci 26:676-682.

Wichterle H, Garcia-Verdugo JM, Herrera DG, Alvarez-Buylla A (1999) Young neurons from medial ganglionic eminence disperse in adult and embryonic brain. Nat Neurosci 2:461-466.

Wichterle H, Turnbull DH, Nery S, Fishell G, Alvarez-Buylla A, GarciaVerdugo JM, Herrera DG (2001) In utero fate mapping reveals distinct migratory pathways and fates of neurons born in the mammalian basal forebrain. Development 128:3759-3771.

Wonders C, Anderson SA (2005) Cortical interneurons and their origins. Neuroscientist 11:199-205.

Xu Q, de la Cruz E, Anderson SA (2003) Cortical interneuron fate determination: diverse sources for distinct subtypes? Cereb Cortex 13:670-676.

Xu Q, Cobos I, De La Cruz E, Rubenstein JL, Anderson SA (2004) Origins of cortical interneuron subtypes. J Neurosci 24:2612-2622.

Yau HJ, Wang HF, Lai C, Liu FC (2003) Neural development of the neuregulin receptor ErbB4 in the cerebral cortex and the hippocampus: preferential expression by interneurons tangentially migrating from the ganglionic eminences. Cereb Cortex 13:252-264.

Yozu M, Tabata H, Nakajima K (2005) The caudal migratory stream: a novel migratory stream of interneurons derived from the caudal ganglionic eminence in the developing mouse forebrain. J Neurosci $25: 7268-7277$

Yuste R (2005) Origin and classification of neocortical interneurons. Neuron 48:524-527.

Zhao Y, Marin O, Hermesz E, Powell A, Flames N, Palkovits M, Rubenstein JL, Westphal H (2003) The LIM-homeobox gene Lhx8 is required for the development of many cholinergic neurons in the mouse forebrain. Proc Natl Acad Sci USA 100:9005-9010. 